\title{
Heterogeneous freezing of water droplets containing kaolinite particles
}

\author{
B. J. Murray ${ }^{1,{ }^{* *}}$, S. L. Broadley ${ }^{1, * *}$, T. W. Wilson ${ }^{1}$, J. D. Atkinson ${ }^{1, * *}$, and R. H. Wills ${ }^{1, *}$ \\ ${ }^{1}$ School of Chemistry, University of Leeds, Woodhouse Lane, Leeds LS2 9JT, UK \\ * now at: Department of Chemistry, University of Warwick, Gibbet Hill Road, Coventry CV4 7AL, UK \\ ** now at: School of Earth and Environment, University of Leeds, Woodhouse Lane, Leeds LS2 9JT, UK
}

Received: 1 April 2010 - Published in Atmos. Chem. Phys. Discuss.: 16 April 2010

Revised: 30 March 2011 - Accepted: 1 April 2011 - Published: 6 May 2011

\begin{abstract}
Clouds composed of both ice particles and supercooled liquid water droplets exist at temperatures above $\sim 236 \mathrm{~K}$. These mixed phase clouds, which strongly impact climate, are very sensitive to the presence of solid particles that can catalyse freezing. In this paper we describe experiments to determine the conditions at which the clay mineral kaolinite nucleates ice when immersed within water droplets. These are the first immersion mode experiments in which the ice nucleating ability of kaolinite has been determined as a function of clay surface area, cooling rate and also at constant temperatures. Water droplets containing a known amount of clay mineral were supported on a hydrophobic surface and cooled at rates of between 0.8 and $10 \mathrm{~K} \mathrm{~min}^{-1}$ or held at constant sub-zero temperatures. The time and temperature at which individual 10-50 $\mu \mathrm{m}$ diameter droplets froze were determined by optical microscopy. For a cooling rate of $10 \mathrm{~K} \mathrm{~min}^{-1}$, the median nucleation temperature of $10-40 \mu \mathrm{m}$ diameter droplets increased from close to the homogeneous nucleation limit $(236 \mathrm{~K})$ to $240.8 \pm 0.6 \mathrm{~K}$ as the concentration of kaolinite in the droplets was increased from $0.005 \mathrm{wt} \%$ to $1 \mathrm{wt} \%$. This data shows that the probability of freezing scales with surface area of the kaolinite inclusions. We also show that at a constant temperature the number of liquid droplets decreases exponentially as they freeze over time. The constant cooling rate experiments are consistent with the stochastic, singular and modified singular descriptions of heterogeneous nucleation; however, freezing during cooling and at constant temperature can be reconciled best with the stochastic approach. We report temperature dependent nucleation rate coefficients (nucleation events per unit
\end{abstract}

Correspondence to: B. J. Murray

(b.j.murray@leeds.ac.uk) time per unit area) for kaolinite and present a general parameterisation for immersion nucleation which may be suitable for cloud modelling once nucleation by other important ice nucleating species is quantified in the future.

\section{Introduction}

In the absence of appropriate ice nuclei, cloud water droplets will supercool to around $236 \mathrm{~K}$ at which temperature they spontaneously freeze. The presence of suitable solid particles, known as ice nuclei, can heterogeneously catalyse ice formation at much higher temperatures. Ice nuclei tend to be rare in comparison to cloud condensation nuclei (DeMott et al., 2003a, 2010) and ice particles resulting from heterogeneous nucleation may grow at the expense of any unfrozen droplets. This results in a shift to lower number densities of larger particles which has a profound impact on cloud lifetimes and radiative properties as well as precipitation (Pruppacher and Klett, 1997; Lohmann and Feichter, 2005). Hence, a fundamental understanding of ice nucleation by atmospherically relevant ice nuclei is key for quantifying the role of clouds in the climate system and the hydrological cycle.

Heterogeneous freezing has been hypothesised to occur in four different modes: deposition nucleation, condensation freezing, immersion freezing, and contact freezing (Vali, 1985; Pruppacher and Klett, 1997). Deposition nucleation occurs when vapour adsorbs onto a solid surface and is transformed into ice. It is thought to be less important than the other mechanisms in mixed phase clouds (Lohmann and Diehl, 2006), but is likely to be important in upper tropospheric ice clouds (DeMott, 2002). Immersion freezing

Published by Copernicus Publications on behalf of the European Geosciences Union. 
occurs when ice nucleates on a solid particle immersed in a supercooled liquid droplet, whereas condensation freezing occurs when water vapour condenses on to a solid particle and then freezes. The distinction between immersion and condensation modes is subtle, since the most likely route for immersing a particle inside a droplet is through condensation on that particle. Contact freezing occurs when a solid particle collides with a supercooled liquid droplet, resulting in ice nucleation. Immersion mode and contact freezing are thought to be most important in many mixed phase clouds (Lohmann and Diehl, 2006; de Boer et al., 2010). Nucleation of ice or droplets directly from the vapour phase without the need for aerosol is not thought to be important in the troposphere, but may be important in the mesosphere (Murray and Jensen, 2010).

The identity, concentration, global distribution and the efficiency with which potential ice nuclei catalyse ice formation are all poorly quantified at present. Mineral dust is known to be an important class of ice nuclei and is transported many thousands of miles from arid source regions (DeMott et al., 2003b; Sassen, 2005). On the order of $10^{15} \mathrm{~g}$ of dust particles with diameters less than $10 \mu \mathrm{m}$ are injected into the Earth's atmosphere per annum from surface sources such as deserts (Denman et al., 2007). Approximately 50\% of the dust from Asia is transported as far as the Pacific and continental USA (Zhang et al., 1997). African dust is known to be transported over the Atlantic and is found in the Caribbean (Usher et al., 2003; Glaccum and Prospero, 1980) and 40 million tons of African dust is transported annually to the Amazon basin where it acts as an important fertiliser (Koren et al., 2006). Furthermore, there has been a two to four fold increase in airborne mineral dust in the North Atlantic region since the 1960s and this is possibly linked to human activities (Mahowald and Kiehl, 2003).

Ice nucleation on mineral dust is known to impact cloud formation on a planetary scale, but its quantitative impact on climate and precipitation remains poorly defined (Denman et al., 2007). Mineral dust suspended in the Earth's atmosphere is made up of a range of minerals (Glaccum and Prospero, 1980; Kandler et al., 2007); however the ice nucleating potential of individual minerals is poorly characterised. Early studies where residues of snowflakes were analysed by electron microscopy demonstrated that clay minerals were present inside 28 to $88 \%$ of snowflakes, depending on location (Pruppacher and Klett, 1997). More recently, single particle mass spectrometry has shown that mineral dusts and metallic particles are substantially enhanced in the fraction of aerosol that nucleate ice heterogeneously, relative to the background aerosol (DeMott et al., 2003a, b; Richardson et al., 2007; Mertes et al., 2007; Pratt et al., 2009). Richardson et al. (2007) demonstrated that mineral dust represented only a few percent of the total background aerosol, but represented $\sim 1 / 3$ of the particles that served as ice nuclei in mixed phase clouds. Prenni at al. (2009) showed that, in the Amazon region where ice nucleation is dominated by biogenic material above $248 \mathrm{~K}$, ice nucleation on mineral dust becomes increasingly important below $246 \mathrm{~K}$.

In the first global modelling sensitivity study of its kind, Lohmann and Diehl (2006) studied the impact of two clay minerals on stratiform mixed phase clouds and found the subsequent radiative forcing to be between 1.0 and $2.1 \mathrm{~W} \mathrm{~m}^{-2}$; comparable to the forcing by anthropogenic $\mathrm{CO}_{2}\left(1.7 \mathrm{~W} \mathrm{~m}^{-2}\right)$. In addition, Lohmann and Diehl (2006) demonstrated that there is a strong sensitivity to dust type, of $1.1 \mathrm{~W} \mathrm{~m}^{-2}$, in going from montmorillonite to kaolinite. The parameterisation of immersion mode nucleation Lohmann and Diehl (2006) used in their global modelling study was based on experimental data reported in the 1960s (Hoffer, 1961) and 1970s (Pitter and Pruppacher, 1973). In neither of these papers was the quantity or surface area of mineral dusts present in their droplets reported and the nucleation temperatures quoted for the same minerals varied by $5-10 \mathrm{~K}$ between the papers. The parameterisation therefore did not include a surface area or time dependence partly because this information was not available and partly as a simplification for the purpose of modelling.

In this paper we present measurements of the efficiency with which the clay mineral kaolinite nucleates ice when immersed in water droplets. We show that the median freezing temperature of droplets containing kaolinite scale with the surface area of the solid inclusion. We also report ice nucleation under isothermal conditions which shows that nucleation by kaolinite in the immersion mode is time dependent. Our data is then fitted to the stochastic, singular and modified singular models for comparison. Finally, we outline a multiple component stochastic model which may be useful for modelling, once temperature dependent nucleation rate coefficients are determined for the major atmospherically relevant ice nuclei.

\section{Methodology}

The equipment used to make these measurements has been described previously and has been used to investigate homogeneous freezing (Murray et al., 2010), heterogeneous freezing by meteoric smoke (Saunders et al., 2010), freezing of water in jet aviation fuel (Murray et al., 2011) and phase changes in iodic acid solutions (Kumar et al., 2010). Briefly, the droplets were supported on a hydrophobic surface positioned on a custom made cold stage which was coupled to a commercial optical transmission microscope with a 10x objective. For these experiments we could control the cooling rate between 0.8 to $10 \mathrm{~K} \mathrm{~min}^{-1}$ and also hold the temperature constant for up to $\sim 70 \mathrm{~min}$. Droplet freezing temperatures/times were determined from images recorded using a digital camera coupled to the microscope. We estimate that our temperature uncertainty is $0.6 \mathrm{~K}$ which accounts for the random error from the thermocouple and the uncertainty in timing between the video and temperature measurement log. 
In order to measure ice nucleation quantitatively, special care was taken in generating the droplets. Droplets containing a known quantity of mineral dust were produced using a home-made nebuliser similar in design to one used by Pant et al. (2006). The nebuliser did not become blocked by clay particles for the range of concentrations of the dust-in-water suspensions used in these experiments. The concentration of dust in the suspensions was determined gravimetrically and the dust was suspended by mixing for at least $12 \mathrm{~h}$ with a magnetic stirring bead. We did not use more vigorous mixing methods, such as high speed mixers or sonic baths, in order to minimise modification of the dust grains. The suspensions were produced using ultra-pure water (18.2 M $\Omega$ ).

The suspensions were nebulised into a chamber which was maintained at water saturation by means of an additional saturated flow of nitrogen gas. This ensured that the droplets did not grow or shrink through evaporation or condensation once they exited the nebuliser. We therefore assumed that the mineral dust concentration was fixed at the value of the original suspension. Droplets were then allowed to settle onto a glass cover slip which was placed within the chamber. The borosilicate glass cover slip was coated with a hydrophobic organosilane. This substrate had a contact angle of $100^{\circ}$ and ensured the surface did not interfere with ice nucleation (Dymarska et al., 2006; Knopf and Lopez, 2009; Koop et al., 1998; Eastwood et al., 2009; Murray et al., 2010). The same procedure was used to examine homogeneous nucleation and the resulting nucleation rates were in good agreement with literature data, thus confirming that the surface did not initiate crystallisation (Murray et al., 2010).

Two styles of experiment were performed, one in which droplets were surrounded by $\mathrm{N}_{2}$ gas and the other where droplets were encased in silicone oil. In the former experiment, a second cover slip with a spacer was placed over the first cover slip to encase the droplets in the $\mathrm{N}_{2}$-filled space between the cover slips (i.e. the droplets were not in contact with the top cover slip). The amount of water vapour around the droplets was insufficient to significantly alter the concentration of the clay in the droplets as the cell was cooled, hence the dust concentration was fixed. This approach was used for experiments with a cooling rate of $10 \mathrm{~K} \mathrm{~min}^{-1}$. However, for cooling rates slower than $10 \mathrm{~K} \mathrm{~min}^{-1}$ mass transfer from supercooled droplets to frozen droplets resulted in liquid droplets shrinking and sometimes disappearing. To prevent mass transfer from supercooled water to ice particles a drop of silicone oil was placed over the water droplets with a pipette. This encased the droplets in oil and greatly reduced mass transfer on the timescales explored here and allowed experiments with slower cooling rates than was otherwise possible. Droplet-containing cells were then transferred to the cold stage where ice nucleation was measured. In some cases freezing resulted in a spike of ice breaking out of the freezing droplet. This did not occur when droplets were surrounded by $\mathrm{N}_{2}$ gas. Any supercooled droplets that happened to be close enough to come into contact with a spike also froze, and care was taken to disregard these droplets from our analysis. It is shown below that nucleation rate coefficients from experiments with and without oil are in good agreement.

\section{Materials}

Our approach was to measure the ice nucleating efficiency of a well characterised kaolinite sample which was predominantly composed of a single mineral. Natural dusts and Arizona Test Dust (ATD), the commonly employed proxy for natural dusts, are complex mixtures of minerals and each mineral may have distinct ice nucleating characteristics. Marcolli et al. (2007) also suggest there is dependence on the size distribution of mineral particles. The kaolinite $\left(\mathrm{Al}_{4}(\mathrm{OH})_{8} \mathrm{Si}_{4} \mathrm{O}_{10}\right)$ used in this study was sourced from the Clay Mineral Society. This society make available well characterised clay mineral samples for research purposes which have not been acid washed or otherwise chemically treated (see Costanzo et al. (2001) and related special issue), unlike clays from chemical companies sometimes employed in other studies (Zuberi et al., 2002; Lüönd et al., 2010). We used Kaolinite KGa-1b and pertinent details are given in Table 1.

\section{Results}

Using the optical microscope images we determined the number of droplets frozen as a function of temperature during cooling and as a function of time at constant temperature. Only droplets in the $10-50 \mu \mathrm{m}$ size range were considered and in many experiments there were sufficient droplets to split the data into much smaller size bins (the minimum number of droplets per size bin was 16 , but there were usually many more; see Table 2 ). The fraction frozen is defined as $f_{\text {ice }}(T)=n(T) / N_{0}$, where $n(T)$ is the number of droplets frozen at temperature $T$ and $N_{0}$ is the initial number of liquid droplets. Plots of $f_{\text {ice }}$ for pure water droplets (from Murray et al., 2010) and droplets containing kaolinite (i-vi: all for $10-40 \mu \mathrm{m}$ diameter droplets) are shown in Fig. 1. The cooling rate for all the runs shown in Fig. 1 was $10 \mathrm{~K} \mathrm{~min}^{-1}$.

Pure water droplets $(10-40 \mu \mathrm{m})$ were previously found to freeze homogeneously with a median freezing temperature $\left(T_{\mathrm{f}}\right)$ of $235.5 \pm 0.6 \mathrm{~K}$ for a cooling rate of $10 \mathrm{~K} \mathrm{~min}^{-1}$ using the apparatus employed here (Murray et al., 2010). In contrast, droplets containing kaolinite froze between $235.5 \pm 0.6 \mathrm{~K}$ and $240.8 \pm 0.6 \mathrm{~K}$ (median freezing temperatures when cooled at $10 \mathrm{~K} \mathrm{~min}^{-1}$ ) depending on the concentration of kaolinite present; the more kaolinite the higher the freezing temperature. This is illustrated in Fig. 2, which shows that $T_{\mathrm{f}}$ increased with increasing surface area of kaolinite within the droplets for a constant cooling rate. The surface area of kaolinite was varied by changing the concentration of kaolinite suspended in the droplets and holding 
Table 1. Properties of "as shipped" kaolinite used in this study.

\begin{tabular}{|c|c|c|c|}
\hline Mineral & Purity & Major impurities & Surface area $/ \mathrm{m}^{2} \mathrm{~g}^{-1}$ \\
\hline \multirow[t]{2}{*}{ Kaolinite (KGa-1b) } & $96 \%$ & $\begin{array}{l}\text { Anatase, } \\
\text { crandallite, mica, illite. }\end{array}$ & $\begin{array}{l}\text { 13.1 }\left(\mathrm{N}_{2} \text { BET }^{\mathrm{a}}\right) \\
\text { Dogan et al. }(2006) \\
11.3\left(\mathrm{AFM}^{\mathrm{b}}\right) \\
\text { Bickmore et al. (2002) } \\
12.5\left(\mathrm{~N}_{2} \text { BET }^{\mathrm{a}}\right) \\
\left.\text { Bereznitski et al. (1998) }_{1} \text { (N }_{2} \text { BET }^{\mathrm{a}}\right) \\
\text { Jaynes et al. (2005) } \\
\left.12 \text { (EGME }^{\mathrm{c}}\right) \\
\text { Jaynes et al. }(2005) \\
11.4\left(\mathrm{~N}_{2} \text { BET }^{\mathrm{a}}\right) \\
\text { Foster et al. }(1998) \\
11.4\left(\mathrm{~N}_{2} \text { BET }^{\mathrm{a}}\right) \\
\text { Thompson et al. (1999) }\end{array}$ \\
\hline & & & Average $=11.8 \pm 0.8$ \\
\hline
\end{tabular}

a BET $=$ Brunauer, Emmett and Teller gas adsorption technique (Gregg and Sing, 1982).

b $\mathrm{AFM}=$ Atomic force microscopy

${ }^{\mathrm{c}}$ EGME = Ethylene Glycol Monoethyl Ether adsorption.

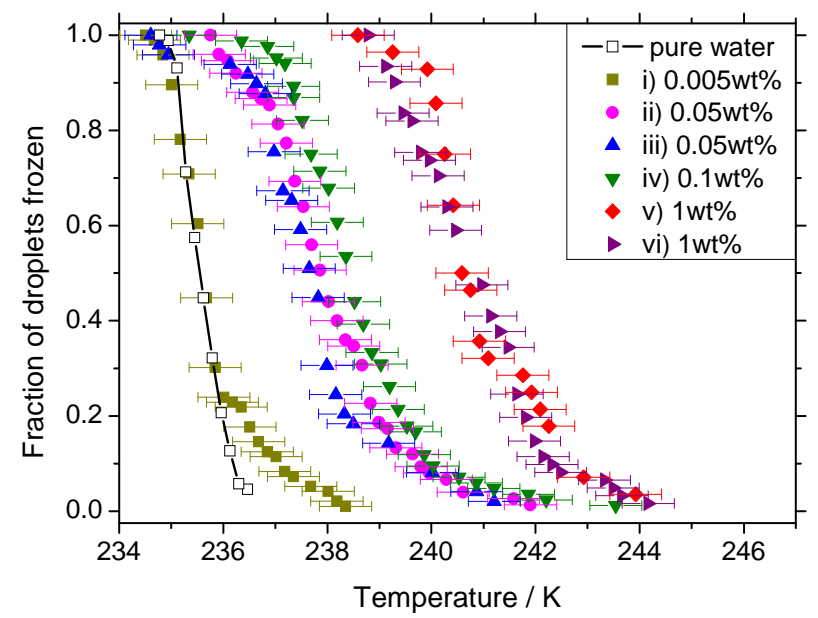

Fig. 1. Fraction of droplets frozen as a function of temperature as water droplets containing known concentrations of kaolinite were cooled down at $10 \mathrm{~K} \mathrm{~min}^{-1}$. Median droplet size was held almost constant in these experiments (see Table 2). The data for pure water (homogeneous) is from Murray et al. (2010).

the median droplet volume almost constant (the volume varied by less than a factor of two in a non-systematic manner for the runs at $10 \mathrm{~K} \mathrm{~min}^{-1}$, see Table 2). In some model parameterisations (Diehl et al., 2006; Pruppacher and Klett, 1997; Bigg, 1953), ice nucleation is defined in terms of droplet volume; whereas in others nucleation is related to surface area within droplets (Hoose et al., 2010; Khvorostyanov and Curry, 2005, 2004; Phillips et al., 2008). For kaolinite, Fig. 2 shows that nucleation probability is related to the surface area of the solid particles suspended within the droplets.

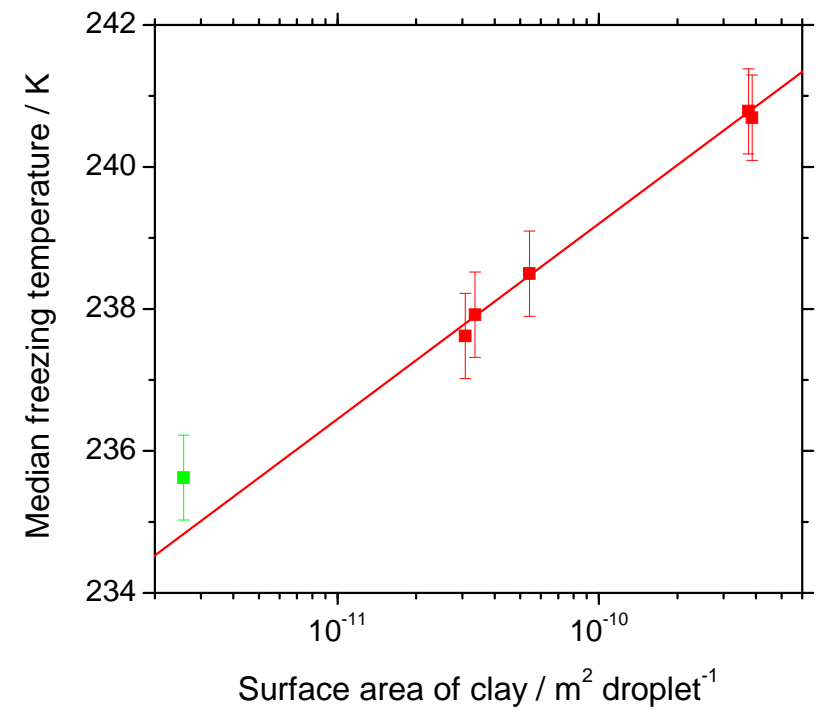

Fig. 2. The median freezing temperature $\left(T_{\mathrm{f}}\right)$ as a function of the kaolinite surface area. The surface area is calculated for the median volume droplet, for cooling rate experiments which contained droplets in the $10-40 \mu \mathrm{m}$ size range (i to vi). Experiments performed at $10 \mathrm{~K} \mathrm{~min}^{-1}$ (runs ii-vi) are shown in red and the red line is a fit to these data $\left(T_{\mathrm{f}}=2.75 \log (\sigma+266.7)\right)$. Run i was also performed at $10 \mathrm{~K} \mathrm{~min}^{-1}$ (shown in green) but was omitted from the fit since some of the droplets froze in a temperature regime in which homogeneous freezing was expected (see Fig. 1). For these experiments, the surface area of kaolinite inclusions was varied by changing the concentration of kaolinite suspended in water and the median volume of the droplets only varied within a factor of two between runs.

Experiments were also performed with cooling rates slower than $10 \mathrm{~K} \mathrm{~min}^{-1}$ in which droplets were surrounded by oil (see Table 2 for a summary). Two runs were performed at a constant cooling rate of around $5 \mathrm{~K} \mathrm{~min}^{-1}$ and in another run the cooling rate was varied throughout the experiment. The runs labelled viii to xi were performed with the same droplets of $1.0 \mathrm{wt} \%$ kaolinite, but where the droplets were initially cooled at a rate of $9.6 \mathrm{~K} \mathrm{~min}^{-1}$, followed by a rate of $0.8 \mathrm{~K} \mathrm{~min}^{-1}$. The droplets were then held at $242 \mathrm{~K}$ for $80 \mathrm{~s}$ before finally being cooled at $5.1 \mathrm{~K} \mathrm{~min}^{-1}$ to $228 \mathrm{~K}$.

An additional sequence of experiments were performed where the droplets were cooled to a specific temperature and then held at that temperature. The fraction of droplets which were liquid $\left(N(t) / N_{0}\right.$; where $N(t)$ is the number of liquid droplets at time $t$ and $N_{0}$ is the number of liquid droplets at the beginning of the isothermal experiment) is shown as a function of time during these isothermal experiments in Fig. 3. 
Table 2. Parameters for each experiment used in the calculation of nucleation rates. In some experiments droplet distributions were split into two size bins which are labelled $a$ and $b$.

\begin{tabular}{|c|c|c|c|c|c|c|c|c|c|c|}
\hline Experiment & & $\begin{array}{c}\text { Concentration/ } \\
\text { wt } \%\end{array}$ & $\begin{array}{c}\text { Size Bin } \\
\text { (diameter) } / \mu \mathrm{m}\end{array}$ & $\begin{array}{l}\text { Cooling rate/ } \\
\mathrm{K} \mathrm{min}^{-1}\end{array}$ & $\begin{array}{l}\text { Median volume } \\
\quad / 10^{-9} \mathrm{~cm}^{3}\end{array}$ & $\begin{array}{l}\text { Median volume } \\
\text { diameter } \mathrm{b} / \mu \mathrm{m}\end{array}$ & $\begin{array}{c}\text { Surface area of clay } \\
\text { per droplet } / \mathrm{cm}^{2}\end{array}$ & $\begin{array}{l}\text { Spherical equivalent } \\
\text { radius of clayc } / \mu \mathrm{m}\end{array}$ & $\begin{array}{c}\text { Number of } \\
\text { droplets }\end{array}$ & $\begin{array}{l}\text { Estimated number } \\
\text { of particles per } \\
\text { median droplet }^{\mathrm{d}}\end{array}$ \\
\hline i & & 0.005 & $10-40$ & 10 & 4.38 & 20.3 & $2.59 \times 10^{-8}$ & 0.45 & 96 & 22 \\
\hline ii & & 0.05 & $10-40$ & 10 & 5.69 & 22.2 & $3.36 \times 10^{-7}$ & 1.63 & 74 & 286 \\
\hline iii & & 0.05 & $10-40$ & 10 & 5.22 & 21.5 & $3.09 \times 10^{-7}$ & 1.58 & 49 & 262 \\
\hline iv & & 0.1 & $10-40$ & 10 & 4.54 & 20.6 & $5.37 \times 10^{-7}$ & 2.07 & 82 & 457 \\
\hline $\mathrm{v}$ & & 1.0 & $10-40$ & 10 & 3.25 & 18.4 & $3.84 \times 10^{-6}$ & 5.53 & 29 & 3270 \\
\hline vi & & 1.0 & $10-40$ & 10 & 3.15 & 18.2 & $3.72 \times 10^{-6}$ & 5.44 & 61 & 3160 \\
\hline \multirow[t]{2}{*}{ vii } & $\mathrm{a}$ & 0.34 & $10-20$ & 5.4 & 1.19 & 13.1 & $4.83 \times 10^{-7}$ & 1.96 & 222 & 203 \\
\hline & $\mathrm{b}$ & & $22-40$ & & 7.49 & 24.3 & $3.04 \times 10^{-6}$ & 4.92 & 51 & 2559 \\
\hline \multirow[t]{2}{*}{ viii } & $\mathrm{a}$ & 1.0 & $10-24$ & 9.6 & 2.27 & 16.3 & $2.68 \times 10^{-6}$ & 4.62 & 49 & 2288 \\
\hline & $\mathrm{b}$ & & $26-50$ & & 22.8 & 35.2 & $2.69 \times 10^{-5}$ & 14.61 & 40 & 22944 \\
\hline \multirow[t]{2}{*}{ ix } & $\mathrm{a}$ & 1.0 & $10-24$ & 0.8 & 2.21 & 16.2 & $2.59 \times 10^{-6}$ & 4.54 & 43 & 2218 \\
\hline & b & & $26-50$ & & 12.6 & 28.9 & $1.48 \times 10^{-5}$ & 10.86 & 16 & 12666 \\
\hline $\mathrm{x}$ & & 1.0 & $10-24$ & $\begin{array}{c}\text { isothermal, } \\
242.2 \mathrm{~K}\end{array}$ & 2.12 & 15.9 & $2.49 \times 10^{-6}$ & 4.45 & 35 & 2127 \\
\hline $\mathrm{xi}$ & & 1.0 & $10-24$ & 5.1 & 1.52 & 14.3 & $1.78 \times 10^{-6}$ & 3.77 & 16 & 1523 \\
\hline xii & & 0.23 & $10-22$ & 5.0 & 1.10 & 12.8 & $2.98 \times 10^{-7}$ & 1.54 & 88 & 255 \\
\hline xiii & & 0.23 & $10-20$ & $\begin{array}{l}\text { isothermal } \\
240.2 \mathrm{~K}\end{array}$ & 1.65 & 14.7 & $4.45 \times 10^{-7}$ & 1.88 & 32 & 381 \\
\hline xiv & & 1.11 & $10-20$ & $\begin{array}{c}\text { isothermal } \\
244.1 \mathrm{~K}\end{array}$ & 1.73 & 14.9 & $2.25 \times 10^{-6}$ & 4.24 & 25 & 1926 \\
\hline $\mathrm{xv}$ & & 0.23 & $10-24$ & $\begin{array}{c}\text { isothermal } \\
248.4 \mathrm{~K}\end{array}$ & 1.79 & 15.1 & $4.87 \times 10^{-7}$ & 1.97 & 36 & 412 \\
\hline
\end{tabular}

\footnotetext{
${ }^{a}$ The median droplet volume taking into account the contact angle of the droplets with the surface. ${ }^{b}$ This is the equivalent diameter of spheres determined from the volume in the preceding column. ${ }^{\mathrm{c}}$ This is the radius of a spherical clay particle which would have the same surface area as the collection of smaller particles in a median droplet sized in our experiments. ${ }^{\mathrm{d}}$ Equal to the surface area per droplet divided by the surface area of a mean kaolinite particle. The mean spherical equivalent radius of particles is related to the specific surface area by radius $=3 /$ density/specific surface area. The mean spherical radius was $0.097 \mu \mathrm{m}$ for kaolinite using the density of $2.63 \mathrm{~g} \mathrm{~cm}^{-3}$ and the surface area of the mean spherical kaolinite particle is therefore $1.18 \times 10^{-9} \mathrm{~cm}^{2}$.
}

\section{Comparison of freezing temperatures with literature data}

There are only a handful of literature reports of immersion mode ice nucleation for kaolinite and this data is generally poorly quantified in terms of the amount of particulate material per droplet. Pitter and Pruppacher (1973) found a $T_{\mathrm{f}}$ of $248 \mathrm{~K}$ for droplets contaminated with kaolinite particles. These droplets were $325 \mu \mathrm{m}$ in radius and the clay particle diameter varied from 0.1 to $30 \mu \mathrm{m}$ with a mode diameter of between $1-2 \mu \mathrm{m}$. Freezing occurred over a range of $\sim 14 \mathrm{~K}$ in contrast to our experiments where freezing occurred within $\sim 5 \mathrm{~K}$ for any one clay concentration and cooling rate.

Hoffer (1961) reported median freezing temperatures of $240.7 \mathrm{~K}$ for $\sim 50 \mu \mathrm{m}$ radius droplets containing an unknown quantity of kaolinite. This result, with droplets of a comparable size to our experiments, is within our concentration dependent spread of freezing temperatures.

Freezing of millimetre-sized droplets containing kaolinite was reported by Hama and Itoo (1953). They quote a median freezing temperature of $263 \mathrm{~K}$, although their freezing range overlapped with that for distilled water, indicating their water was not free of other ice nuclei. In general, the literature data suggests that the larger the droplets, the higher the freezing temperature. It is likely that the larger droplets simply con- tained a greater surface area of kaolinite and therefore froze at higher temperatures. Unfortunately, Hoffer (1961), Pitter and Pruppacher (1973) and Hama and Itoo (1953) did not report the concentration of mineral dusts in their droplets.

In a recent study, Lüönd et al. (2010) report the fraction of droplets containing single particles of kaolinite which froze as a function of temperature. They size-segregated the clay particles and reported that $50 \%$ of droplets containing particles with a mobility diameter of $200 \mathrm{~nm}$ froze when held at $238 \mathrm{~K}$ for $14 \mathrm{~s}$, while for $800 \mathrm{~nm}$ particles the same fraction froze at $240 \mathrm{~K}$ for the same residence time. Since Lüönd et al. (2010) did their experiments under different condition to ours we cannot make a comparison at this stage, but will revisit their article in Sect. 6.4.

\section{Models of heterogeneous freezing applied to kaolinite}

There are several models currently employed to describe heterogeneous nucleation and it is unclear which is the most suitable for describing ice nucleation by atmospherically relevant materials. The time-dependent stochastic model has been widely applied to homogeneous freezing (e.g. Krämer et al., 1999) and also in some cases to heterogeneous nucleation (e.g. Vonnegut and Baldwin, 1984). However, for 


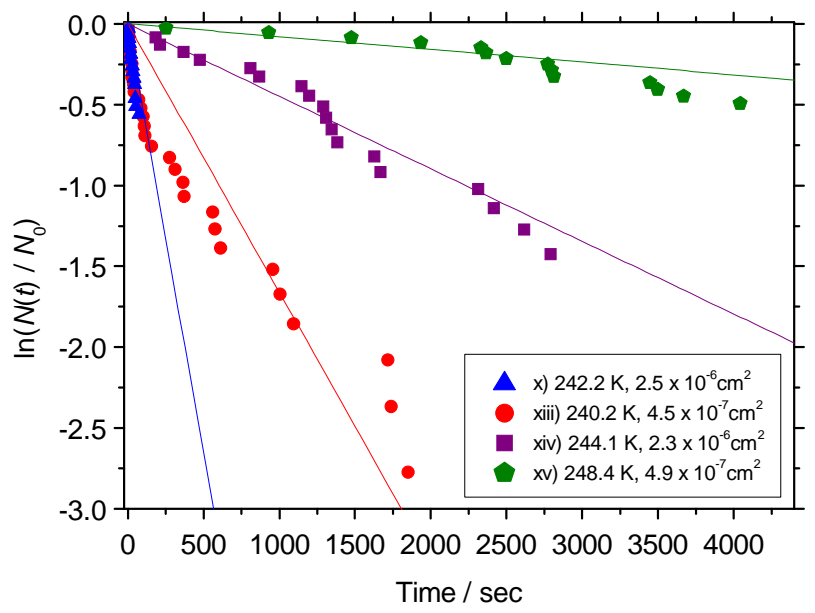

Fig. 3. The decrease in the fraction of droplets which were liquid $\left(N(t) / N_{0}\right)$ with time at constant temperature for a number of temperatures. $N_{0}$ is defined as the number of liquid droplets at the beginning of the isothermal experiment (i.e. excluding any droplets which froze during cooling to the isothermal temperature) and $N(t)$ is the number of liquid droplets at time $t$. The temperature of the isothermal experiment (uncertainty $= \pm 0.6 \mathrm{~K}$ ) and the surface area per median sized droplet is given. The numbering in the key corresponds to the information in Table 2. The straight lines are based on values of $J_{\mathrm{k}}$ determined according to Poisson statistics and are discussed in Sect. 6.1.

the purpose of describing atmospherically relevant ice nuclei, it has been suggested that nucleation can be described by a model in which the time dependence can be neglected (e.g. Connolly, 2009). This model is known as the singular model and it is assumed that time dependence is negligible when compared to the difference in ice nucleating ability of different particles or active sites. The singular description has also been modified empirically to account for the time dependence of nucleation in the modified singular model (e.g. Vali, 1994). In this section we interpret our data according to the stochastic, singular and modified singular models.

\subsection{Stochastic model}

Homogeneous nucleation of ice from liquid water is well described by the stochastic model of ice nucleation (Krämer et al., 1999; Murray et al., 2010; Pruppacher and Klett, 1997). This description is underpinned by the concept of small clusters of the crystalline phase forming from the supercooled liquid phase, but only rarely attaining a size large enough to survive and grow into a macroscopic crystal. Most clusters remain unstable and dissipate back into the liquid phase. The probability of a critical cluster forming is greater for larger volumes of liquid and for longer periods of time. The rate $(R)$ at which liquid droplets freeze can be defined as:

$R=\frac{d N}{d t}=-J_{\mathrm{hom}} V N$ where $d N$ is the number of liquid droplets of volume $V$ which freeze in time $t, J_{\text {hom }}$ is the homogeneous nucleation rate coefficient and $N$ is the number of liquid droplets. In a time interval from $t_{1}$ to $t_{2}$, the number of liquid droplets will decrease from $N_{1}$ to $N_{2}$ :

$\int_{N_{1}}^{N_{2}} \frac{d N}{N}=\int_{t_{1}}^{t_{2}}-J_{\mathrm{hom}} V d t$

This integration yields

$N_{2}=N_{1} \exp \left(-J_{\text {hom }} V \Delta t\right)$

where $\Delta t=t_{2}-t_{1}$. In this model the probability of droplets of the same volume $(V)$ remaining liquid $\left(P=N_{2} / N_{1}\right)$ is equal and a population of identical liquid droplets will decay with time in a manner analogous to the radioactive decay of atoms (Krämer et al., 1999; Stockel et al., 2005):

Experiments show that the homogeneous nucleation rate coefficient $\left(J_{\text {hom }}\right)$ is strongly temperature dependent which leads to the probability of freezing increasing dramatically with decreasing temperature (Murray et al., 2010; Pruppacher and Klett, 1997).

When a suitable solid surface is present, nucleation can be catalysed if clusters of the new phase are stabilised by the presence of the solid. The stochastic model for homogeneous nucleation can be extended to heterogeneous freezing:

$N_{2}=N_{1} \exp \left(-J_{i} \sigma \Delta t\right)$

where $J_{i}$ is the heterogeneous nucleation rate coefficient of species $i$ which we define as the nucleation events per unit surface area $(\sigma)$ of inclusion per droplet per unit time. When extending the homogeneous stochastic model to heterogeneous freezing by a single ice nucleating species it is assumed that the freezing probability is similar for all droplets in a distribution. This uniformity might come about if ice were to nucleate on either characteristic active sites which were evenly distributed amongst the particles (and therefore the droplets) or on the uniform crystal faces exposed on all particles. We refer to this model as the single component stochastic model.

Since the number of droplets which freeze $(\Delta n)$ in a time increment is equal to $N_{1}-N_{2}$, the fraction of droplets frozen in $\Delta t$ can be expressed:

$\frac{\Delta n}{N_{1}}=\left(1-\exp \left(-J_{i} \sigma \Delta t\right)\right)$

If there were more than one particle type or a distribution of active sites then the total number of ice particles produced would be the sum of ice particles produced through nucleation on each ice nucleus type (Marcolli et al., 2007; Stoyanova et al., 1994). We refer to this as the multiple component stochastic model and will expand on this discussion in Sect. 8. 
When droplets containing kaolinite are cooled at a defined rate, the number of droplets which froze heterogeneously in a given time increment $(\Delta t)$ can be expressed by:

$$
\Delta n_{\mathrm{k}}=N_{\mathrm{k}}\left(1-\exp \left(-J_{\mathrm{k}}(T) \sigma \Delta t\right)\right)
$$

where $N_{\mathrm{k}}$ is the number of liquid droplets containing kaolinite at the beginning of a time interval and $J_{\mathrm{k}}$ is the temperature dependent nucleation rate coefficient for kaolinite (per unit area of clay per unit time). Using the experimental fraction of droplets frozen as a function of temperature during cooling (presented in Fig. 1) together with an estimate of the surface area per average droplet we can derive an average $J_{\mathrm{k}}$ for small time intervals and therefore establish the temperature dependence of $J_{\mathrm{k}}$.

The surface area of mineral dust in a droplet of median size was calculated from the concentration of mineral dust in the droplets in combination with the specific surface area of the clay mineral. The specific surface area of the kaolinite samples used here are reported in the literature and are summarised in Table 1. We used the average values from a number of literature sources in our calculations. Gas adsorption techniques are in agreement with atomic force microscopy measurements of surface area for KGa-1b kaolinite (Bickmore et al., 2002). The surface area of kaolinite per median droplet in our experiments was varied from $2.6 \times 10^{-8}$ to $2.7 \times 10^{-5} \mathrm{~cm}^{2}$, which corresponds to equivalent spherical kaolinite particles with radii between 0.45 and $14.6 \mu \mathrm{m}$ (See Table 2 for a summary of the experimental parameters).

The median volume of the droplets for each experiment is presented in Table 2 together with the mean surface area of clay particles per droplet. For the $10 \mathrm{~K} \mathrm{~min}^{-1}$ cooling rate experiments, a $\Delta t$ of $3 \mathrm{~s}$ was used to calculate temperature dependent nucleation rates. A shorter time interval would have had the advantage of improving the temperature resolution of $J_{\mathrm{k}}$, but each time bin would have included less freezing events and so increased the statistical error. Typically, a single experiment contained on the order of 10's of droplets (see Table 2) and between 1 and 35 freezing events were included in each time bin. $J_{\mathrm{k}}$ was only reported for time intervals in which there was at least one freezing event within that time increment as well as in the following or preceding time increment. Hence, sporadic freezing events at the beginning and end of the fraction frozen curves (Fig. 1) were not included in the analysis. In addition, we only determined values of $J_{\mathrm{k}}$ for data above $236.1 \mathrm{~K}$ since homogeneous nucleation becomes increasingly important below this temperature (Murray et al., 2010). Nucleation rate coefficients for kaolinite are shown as a function of temperature in Fig. 4 for the freezing data obtained at cooling rates of $10 \mathrm{~K} \mathrm{~min}^{-1}$ in similar sized droplets. In these experiments the surface area was varied by a factor of 200 , but the nucleation rate coefficients all fall on a single line within the experimental uncertainty. This confirms that the nucleation probability is dependent on the surface area of kaolinite.

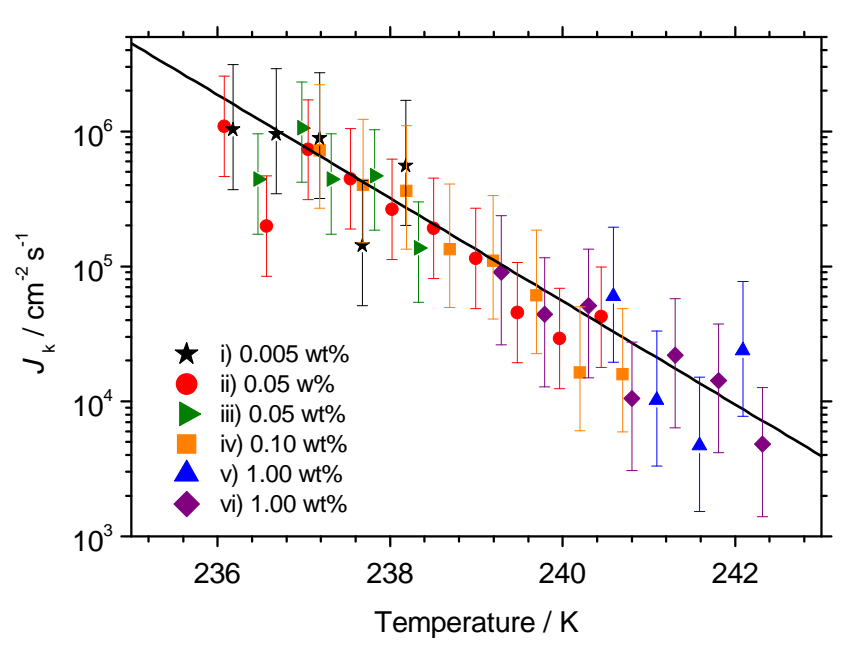

Fig. 4. Nucleation rate coefficients of ice on kaolinite in pure water expressed in units of $\mathrm{cm}^{-2} \mathrm{~s}^{-2}$ based on data obtained with cooling rates of $10 \mathrm{~K} \mathrm{~min}^{-1}$, with varying concentrations of kaolinite. In these experiments droplets were surrounded by $\mathrm{N}_{2}$ gas rather than silicone oil. The black line is a fit to all the kaolinite nucleation data for a range of cooling rates in Fig. 5. The vertical error bars were estimated based on the standard deviation in droplet volume and the specific surface area of the clay (see Table 1). The uncertainty in temperature was $\pm 0.6 \mathrm{~K}$.

Figure 5 shows the nucleation rate coefficients determined from freezing experiments in which a range of cooling rates $\left(0.8\right.$ to $\left.10 \mathrm{~K} \mathrm{~min}^{-1}\right)$ were employed. All the runs with cooling rates less than $10 \mathrm{~K} \mathrm{~min}^{-1}$ were done with droplets surrounded by oil in order to block mass transfer. The values of $J_{\mathrm{k}}$ determined from the variable cooling rate experiments are consistent with those at $10 \mathrm{~K} \mathrm{~min}^{-1}$ and all the $J_{\mathrm{k}}$ values obtained during cooling are fitted in Fig. 5 by a single line.

We have also plotted the nucleation rate coefficients determined from the isothermal experiments in Fig. 5. According to Eq. (6) the number of identical liquid droplets containing a uniform distribution of heterogeneous ice nucleating particles will decrease exponentially with time. However, in order to take into account the time in which no nucleation events took place at the end of an isothermal run it is necessary to employ Poisson statistics as described by Koop et al. (1997). They show that $J=n /\left(t_{\text {tot }} \sigma\right)$ where $t_{\text {tot }}$ is the cumulative (total) observation time (see Koop et al., 1997). Upper and lower confidence limits at the $99.9 \%$ confidence level (following Koop et al., 1997) are combined with uncertainties in $\sigma$ associated with the distribution of droplet sizes to produce the error bars shown in Fig. 5.

Using these nucleation rate coefficients we have plotted the rate of decay of liquid droplets according to Eq. (4) in Fig. 3 for comparison with the experimental data. For runs $\mathrm{x}$ and xiv the data is in very good agreement with Eq. (4), whereas for runs xiii and $\mathrm{xv}$ the agreement is less satisfactory. Run xiii is steeper initially (before $155 \mathrm{~s}$ ), whereas run $\mathrm{xv}$ 


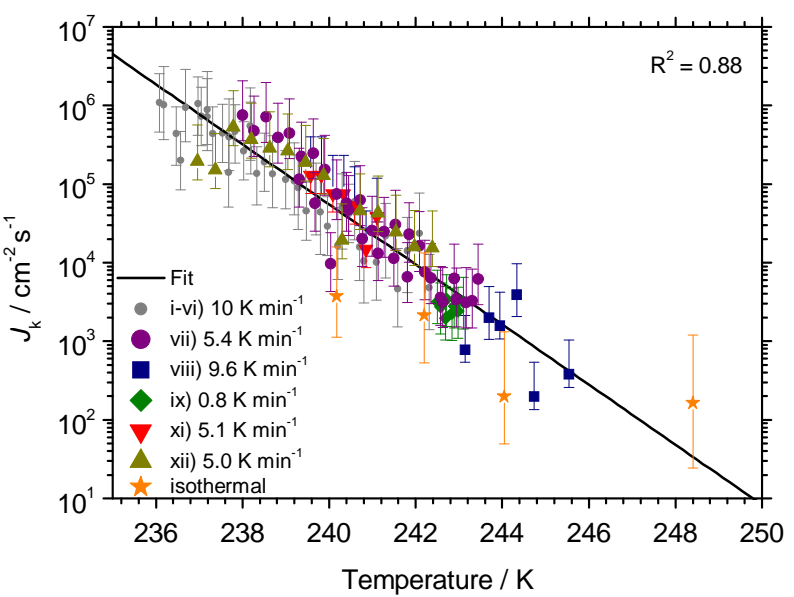

Fig. 5. Nucleation rate coefficients of ice on kaolinite in pure water $\left(J_{\mathrm{k}}\right)$ for a range of cooling rates and isothermal experiments for a range of temperatures based on the stochastic model. The data from Fig. 4 are included as grey small points (i-vi) and are from droplets surrounded by $\mathrm{N}_{2}$ gas. Data labelled vii to xi (and the isothermal experiments) was obtained with droplets surrounded by silicone oil to slow mass transfer form supercooled liquid droplets to frozen droplets. The run labelled vii in the key was a constant cooling run at $5 \mathrm{~K} \mathrm{~min}^{-1}$ with droplets containing $0.34 \mathrm{wt} \%$ kaolinite. Data labelled viii to xi were from the same droplet distribution $(1.0 \mathrm{wt} \%$ kaolinite) which was initially cooled at $9.6 \mathrm{~K} \mathrm{~min}^{-1}$, then at 0.8 $\mathrm{K} \mathrm{min}^{-1}$ to $242 \mathrm{~K}$ where it was held for $80 \mathrm{~s}$, and then to $228 \mathrm{~K}$ at $5.1 \mathrm{~K} \mathrm{~min}^{-1}$. The black line is a best fit to all the cooling ramp data where $\ln J_{\mathrm{k}}=-0.8802 T+222.17$, which is valid between 236 and $245.5 \mathrm{~K}$.

it is more shallow initially (before $2332 \mathrm{~s}$ ). It is also worth noting that run $\mathrm{x}$ was relatively short and we cannot rule out a change in slope at longer times.

A curve which is steeper initially would be expected if some droplets either contained a greater surface area of kaolinite or contained particles which were more efficient ice nuclei (i.e. a distribution of droplet freezing probabilities) (Koop et al., 1997). This might explain the shape of run xiii, but is inconsistent with the other three runs. In fact, the curvature in run $\mathrm{xv}$ (more shallow initially) is the opposite to what one would expect from a distribution of droplet freezing probabilities. It is more likely that instability of the temperature over longer times led to either a positive or negative change in rate. Instability in temperature within our uncertainly limits $( \pm 0.6 \mathrm{~K})$ would produce a change in slope of about a factor of three according to our measured $J_{\mathrm{k}}(T)$. In addition, nucleation in run xiii appears to occur in pulses which would be consistent with a temperature oscillation with nucleation occurring dominantly in the cold phase. Nevertheless, the isothermal data clearly shows that nucleation of ice by kaolinite immersed within water droplets is a time dependent process and that, given the uncertainties, the resulting values of $J_{\mathrm{k}}$ are consistent with the nucleation values from the constant cooling experiments.

\subsection{Singular description}

Atmospheric aerosol particles are known to nucleate ice over a wide range of temperatures since there is significant particle to particle variability (Pruppacher and Klett, 1997). Variability may arise from the diverse composition of atmospheric aerosol or from some particles possessing unique active sites on their surface. In order to describe this complex behaviour it has been suggested that the time dependence of nucleation is of secondary importance when compared to the particle to particle variability and the time dependence of nucleation is therefore neglected in the singular model (Martin, 2000; Pruppacher and Klett, 1997; Connolly et al., 2009). According to this model each droplet will freeze at a characteristic temperature which will depend on the nature of the nuclei it contains. If all droplets contained identical nuclei then all droplets would freeze at the same temperature, whereas if there were a distribution of particle types randomly dispersed throughout the droplets then freezing would occur over a range of temperatures. The characteristic temperature is independent of cooling rate and in addition nucleation will only occur on cooling, ceasing if the temperature is held constant.

According to the singular model, the fraction of droplets frozen in a population of droplets containing the same surface area of solid inclusions can be expressed:

$\frac{n(T)}{N}=1-\exp \left(-n_{\mathrm{s}}(T) \sigma\right)$

where $n_{\mathrm{S}}(T)$ is the number of surface sites per unit area which become active on cooling from $273 \mathrm{~K}$ to $T$ (Connolly et al., 2009). Vali $(1971,1994)$ defines an equivalent parameter as the cumulative nucleus spectrum which is expressed per unit volume of liquid. The number of surface sites per unit area which become active as temperature is lowered by $d T$ is expressed as $k(T)$. Hence, $n_{\mathrm{s}}(T)$ and $k(T)$ are related by:

$n_{\mathrm{S}}(T)=-\int_{T_{0}}^{T} k(T) d T$

$k(T)$ is the differential ice active surface site density $\left(k(T)=d n_{\mathrm{S}}(T) / d T\right)$. Vali $(1971,1994)$ defined $k(T)$ as the differential nucleus spectrum (per unit volume per unit temperature).

Using this model we have determined $n_{\mathrm{s}}(T)$ for our cooling ramp experiments and the resulting values are shown in Fig. 6a. In general, it appears that the slower the cooling rate, the higher the value of $n_{\mathrm{s}}$ for any given temperature. This suggests there is a dependence on cooling rate, although this is weak in comparison to our experimental uncertainty. It was not possible to determine values of $n_{\mathrm{S}}$ for the experiments where temperature was held constant since the singular model is time independent. 

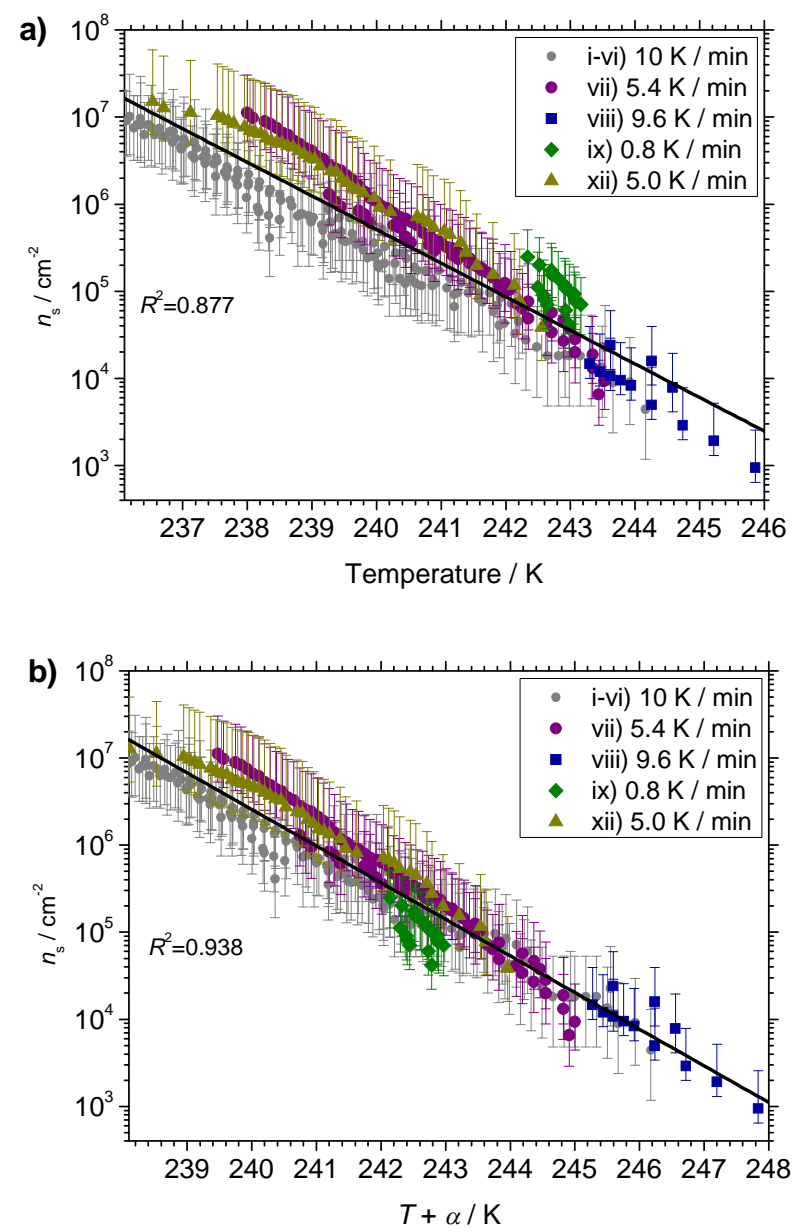

Fig. 6. The ice active surface site density $\left(n_{\mathrm{S}}\right)$ for kaolinite in the immersion mode. Panel (a) illustrates $n_{\mathrm{S}}$ as a function of temperature according to the singular model, whereas panel (b) shows $n_{\mathrm{S}}$ as a function of temperature adjusted for the effects of cooling rate according to the modified singular model ( $\beta$ is set to 2.01). The solid lines are linear best fits to the data and the fit in panel (a) is described by $\ln n_{\mathrm{S}}=-0.8881 T+226.29$. See Sects. 6.2 and 6.3 for details.

\subsection{Modified singular description}

Vali $(1966,1994)$ found that freezing temperatures of distilled water droplets containing unknown ice nuclei were dependent on cooling rate and that nucleation also continued when the temperature was held constant; these features are inconsistent with the singular model. In a later study Vali (2008) went on to show that the freezing temperature of individual droplets containing soil samples varied by several degrees around a characteristic temperature on repeating the freezing experiment with the same droplets; this is also inconsistent with the singular model. In addition the wide range of freezing temperatures and non-exponential decay of liquid droplets under isothermal conditions observed by Vali $(1966,1994,2008)$ cannot be accounted for by the single component stochastic model. Vali $(1994,2008)$ proposed the modified singular model as a means of describing this complex behaviour.

In order to account for the cooling rate dependence of the droplet freezing temperatures Vali (1994) modified the singular model by introducing a temperature offset $\alpha$ :

$\frac{n}{N}=1-\exp \left(-n_{\mathrm{s}}\left(T_{\min }-\alpha\right) \sigma\right)$

The variable $\alpha$ is the temperature offset from a freezing spectrum for a cooling rate of $1 \mathrm{~K} \mathrm{~min}^{-1}$ and is related to the cooling rate $(r)$ with an empirical parameter $\beta$ :

$\alpha=\beta \log (|r|)$

Vali (1994) calculated $\beta$ to be 0.66 based on earlier observations of a $0.2 \mathrm{~K}$ change in mean freezing temperature with a factor of two change in cooling rate for the freezing of distilled water droplet (1966).

In Fig. $6 \mathrm{~b}$ we have applied the modified singular model to our data. We found that a value of $\beta$ of 2.01 provided the best fit between our data and a straight line fit. The $R^{2}$ was increased from 0.877 when $\beta$ was set to zero (i.e. the standard time-independent singular model) to 0.938 . Hence, the modified singular model provides an improved description of nucleation by kaolinite in the immersion mode compared to the singular model.

\subsection{Discussion of heterogeneous ice nucleation models}

The stochastic, singular and modified singular models have been employed to describe ice nucleation by kaolinite in the immersion mode. All three models can be used to approximately describe ice nucleation during cooling over the range of cooling rates employed here. However, the singular model is inconsistent with nucleation at constant temperature since it is a time-independent model. As an extension to the modified singular model Vali (1994) suggests that an additional term can be added when determining the total number of ice particles which form in order to account for nucleation under isothermal conditions. The stochastic model describes ice nucleation by kaolinite for a range of cooling rates and approximates nucleation under isothermal conditions with a single temperature dependent nucleation rate coefficient. Hence, we suggest that the stochastic model provides a more concise description of nucleation by kaolinite in the immersion mode.

In the past it has been shown that other materials also nucleate ice in a manner consistent with the stochastic model. Heneghan et al. (2002, 2001) and Vonnegut and Baldwin (1984) repeatedly froze the same sample of water containing silver iodide crystals. They showed that the fraction of droplets remaining liquid decayed exponentially with time 
which is consistent with the stochastic model. Gerber (1976) showed that the number of liquid droplets contaminated with AgI particles decreased exponentially with time at $259 \mathrm{~K}$ for a range of particle sizes; this is also consistent with the stochastic model.

In order to model the freezing of droplets contaminated with controlled amounts of Arizona Test Dust (ATD), Marcolli et al. (2007) employed classical nucleation theory with a log-normal distribution of contact angles. This is a multicomponent stochastic model in which particle to particle variability is accounted for in the distribution of contact angles. As is shown below in Sect. 7, nucleation by kaolinite can be described by a single contact angle, in contrast to ATD which is a mixture of minerals. In a study using dust collected from an urban location, Stoyanova et al. (1994) were able to model freezing of droplets containing this dust using a multi-component stochastic model by assuming three materials, with three distinct contact angles, dominated ice nucleation.

In a chamber study of ice nucleation by soot particles DeMott (1990) reported the fraction of droplets containing soot which froze as a function of temperature. On varying the cooling rate from 1 to $2 \mathrm{~K} \mathrm{~min}^{-1}$ there was no significant change in fraction frozen indicating that over this range of timescales nucleation by soot can be described by the singular model.

We discussed the results of Lüönd et al. (2010) in Sect. 5 and we can now compare the prediction of our stochastic model with their results (we use the parameterisations presented in Sect. 8 which are based on the data in Fig. 5). Briefly, they found that $50 \%$ of droplets containing $800 \mathrm{~nm}$ diameter (based on electrical mobility) kaolinite particles froze when held at $240 \mathrm{~K}$ for $14 \mathrm{~s}$. Using our model we would expect $50 \%$ of droplets containing $800 \mathrm{~nm}$ spherical particles to kaolinite to freeze at $235.7 \mathrm{~K}$ in this time. The surface area of the particles used by Lüönd et al. (2010) may be larger than an $800 \mathrm{~nm}$ spherical particle, but in order to match Lüönd et al.'s result the surface area of their particle would need to be $\sim 100$ times larger. Alternatively, this discrepancy may be due to the different source of kaolinite used by Lüönd et al. (2010). They used a sample from the chemical and analytical reagent supplier Fluka (parent company: Sigma Aldrich) which may have different properties to the sample from the Clay Minerals Society used here. Lüönd et al. (2010) fit a number of models to their data for the freezing of droplets containing kaolinite, but given the quoted uncertainties it was difficult to state which model worked best. However, they did suggest that the single component stochastic model worked least well.

Niemermeier et al. (2010) recently reported nucleation rate coefficients for Arizona Test Dust immersed in water droplets. In their study, Niedermeier et al. (2010) show that both stochastic and singular models can be used to fit the data. They find a $J$ value of $10^{7} \mathrm{~cm}^{-2} \mathrm{~s}^{-1}$ at $239 \mathrm{~K}$, whereas we report a value of $\sim 10^{5} \mathrm{~cm}^{-2} \mathrm{~s}^{-1}$ at the same temperature for kaolinite. This would appear to indicate that ATD, or at least the component of ATD which nucleates ice, is more active than the kaolinite used here. In both the studies of Lüönd et al. (2010) and Niedermeier et al. (2010) the residence time of the droplets in the cold chamber was held constant, but in order to test stochasticity variable time scales are necessary.

\section{Fitting kaolinite ice nucleation rate coefficients to heterogeneous classical nucleation theory}

In the absence of a solid surface, the energy barrier to the nucleation of an ice crystal from pure water (homogeneous nucleation) can be expressed by:

$\Delta G^{*}=\frac{16 \pi \gamma^{3} \nu^{2}}{3(k T \ln S)^{2}}$

where $\gamma$ is the interfacial energy between ice and supercooled water, $v$ is the molecular volume of water in ice, $k$ is the Boltzmann constant and $S$ is the saturation ratio with respect to ice. $S$ is defined as $P_{l} / P_{\text {ice }}$ (Murray et al., 2010), where $P_{l}$ is the equilibrium vapour pressure over a flat liquid water surface and $P_{\text {ice }}$ is the equilibrium vapour pressure over a flat ice surface. The temperature dependent heterogeneous nucleation rate coefficient $\left(\mathrm{cm}^{-2} \mathrm{~s}^{-1}\right)$ can then be described by an equation in an Arrhenius form:

$J(T)=A_{\text {het }} \exp \left(-\frac{\Delta G^{*} \varphi}{k T}\right)$

where $A_{\text {het }}$ is a pre-exponential factor in units of $\mathrm{cm}^{-2} \mathrm{~s}^{-1}$ and $\varphi$ is the factor by which the presence of a solid surface reduces the height of the energy barrier relative to homogeneous nucleation. This factor can be expressed in terms of an ice nucleating efficiency parameter, $m$ :

$\varphi=\frac{(2+m)(1-m)^{2}}{4}$

The parameter $m$ is equal to $\cos \theta$, where $\theta$ is the contact angle of a spherical ice nucleus in contact with a flat surface. While this concept is useful in terms of deriving simple equations, its physical significance is unclear. Hence we report values of $m$ which can be regarded as a quantitative, semi-empirical, measure of a substance's ability to nucleate ice. A value of $m=1$ would correspond to a perfect ice nucleus $(\varphi=0)$, whereas a value of -1 would indicate that a surface does not nucleate ice $(\varphi=1)$.

Combining Eqs. (11), (12), and (13) we see that the heterogeneous nucleation rate can be expressed as (Mullin, 2001; Pant et al., 2006; Parsons et al., 2006):

$\ln J=\ln A_{\text {het }}-\frac{16 \pi \gamma^{3} v^{2}}{3 k^{3} T^{3}(\ln S)^{2}} \frac{(2+m)(1-m)^{2}}{4}$

Hence, over a narrow range of temperatures a plot of $\ln J$ verses $T^{-3}(\ln S)^{-2}$ yields a linear plot with slope

$M=-\frac{16 \pi \gamma^{3} v^{2}}{3 k^{3}} \frac{(2+m)(1-m)^{2}}{4}$ 
thus providing a means of determining $m$ if $\gamma$ is known, without the need to estimate $A_{\text {het }}$.

There are two crystalline phases of ice that can form at atmospheric pressures and therefore there are two possible solutions to this equation. The stable phase of ice has a hexagonal crystal structure (ice $\mathrm{I}_{\mathrm{h}}$ ), but there is also a metastable phase with a cubic crystal structure (ice $I_{c}$ ) which is thought to form under atmospherically relevant conditions (Murray et al., 2005; Murray and Plane, 2003, 2005; Mayer and Hallbrucker, 1987). Diffraction work has shown that ice $\mathrm{I}_{\mathrm{c}}$ with stacking faults is the phase to nucleate and crystallise from pure water droplets when they freeze homogeneously (Huang and Bartell, 1995; Murray and Bertram, 2006, 2007a; Murray et al., 2005) and also when solution droplets freeze homogeneously (Murray, 2008; Murray and Bertram, 2007b, 2008; Murray et al., 2005). Unfortunately, diffraction studies of droplets freezing heterogeneously have not been done, so it is not known which phase nucleates and initially crystallises.

Ostwald's rule of stages states that a metastable phase should nucleate in preference to a more stable phase (Mullin, 2001; Murray et al., 2005). Indeed, the interfacial energy of the ice $I_{c}$ - supercooled water interface is smaller than that of ice $I_{h}$; this favours the nucleation of ice $I_{c}$ in the case of homogeneous nucleation. However, in the case of heterogeneous nucleation by clay particles we also have to consider the clay - ice interfacial energy, which might favour one or other of the phases depending on how well the respective cluster fits to the structure of the solid surface. In addition, the value of $S$ is larger for ice $\mathrm{I}_{\mathrm{h}}$ than ice $\mathrm{I}_{\mathrm{c}}$ since the latter is metastable (Shilling et al., 2006). Hence, the thermodynamic potential is greater for the more stable phase and above a certain temperature the rate at which ice $\mathrm{I}_{\mathrm{h}}$ nucleates will exceed that at which ice $I_{c}$ nucleates. Since we cannot categorically state which phase nucleates first we analyse our data for both phases in turn. This involves using the appropriate values of $\gamma$ and $S$ for each phase.

Assuming hexagonal ice nucleates. We take a value of $33 \pm 3 \mathrm{~mJ} \mathrm{~m}^{-2}$ for the supercooled water - ice $\mathrm{I}_{\mathrm{h}}$ interfacial energy $\left(\gamma_{\mathrm{Ih}}\right)$ which is based on measurements at $273 \mathrm{~K}$ (Hobbs, 1974). The temperature dependence of this value is thought to be weak (Huang and Bartell, 1995). The saturation ratio with respect to ice $\mathrm{I}_{\mathrm{h}}, S_{\mathrm{Ih}}$, is equal to $P_{\mathrm{liq}} / P_{\mathrm{lh}}$, where $P_{\mathrm{Ih}}$ is the vapour pressure over a flat ice $\mathrm{I}_{\mathrm{h}}$ surface. Values of $P_{\text {liq }}$ and $P_{\mathrm{Ih}}$ are taken from the review of Murphy and Koop (2005). The molecular volume is identical within experimental uncertainty for both ice phases (Dowell and Rinfret, 1960), and we use the parameterisation from Murray and Jensen (Murray and Jensen, 2010).

The resulting plot of $\ln J_{\mathrm{k}}$ vs. $T^{-3}\left(\ln S_{\mathrm{Ih}}\right)^{-2}$ is shown in Fig. 7. These plots yield $m_{\mathrm{Ih}}$ for kaolinite of $0.59 \pm 0.01$, which corresponds to contact angles of $54.1 \pm 0.6^{\circ}$ and $\varphi$ of $0.110 \pm 0.004$.

Assuming cubic ice nucleates. The supercooled water -ice $\mathrm{I}_{\mathrm{c}}$ interfacial energy $\left(\gamma_{\mathrm{Ic}}\right)$ was recently determined through

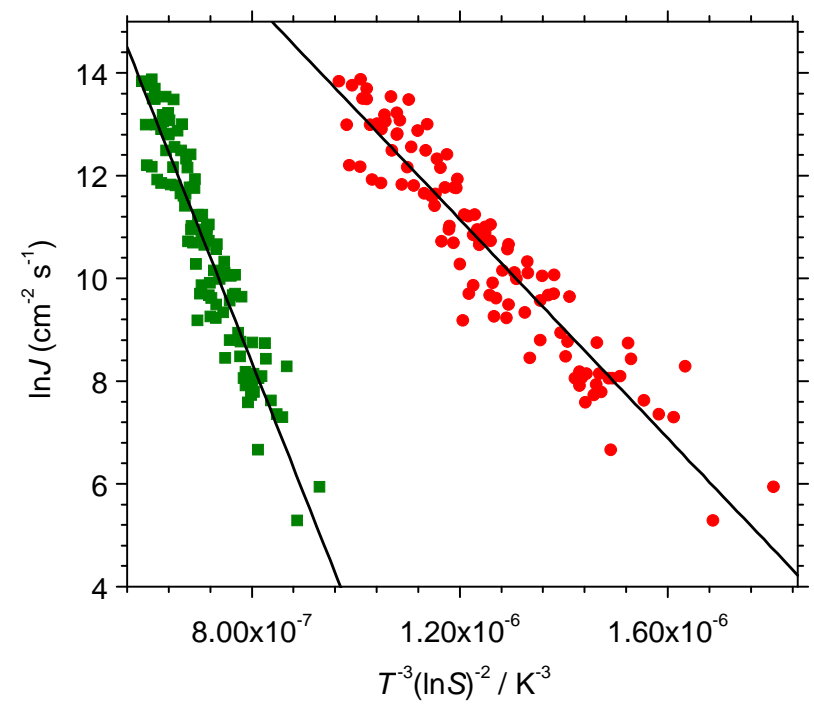

Fig. 7. Nucleation rate of ice on kaolinite as a function of $T^{-3}\left(\ln S_{\text {Ic }}\right)^{-2}\left(\right.$ red circles) and $T^{-3}\left(\ln S_{\mathrm{Ih}}\right)^{-2}$ (green squares). The fits to this data (solid line) yield ice nucleating efficiency parameters, $m$, for the two scenarios. See Sect. 7 for details.

homogeneous freezing experiments to be $20.8 \pm 1.2 \mathrm{~mJ} \mathrm{~m}^{-2}$ (Murray et al., 2010) at $235.8 \mathrm{~K}$ and has a weak temperature dependence. The homogeneous freezing experiments were performed using the same equipment and similar procedures to those employed in the present study. The saturation ratio with respect to ice $\mathrm{I}_{\mathrm{c}}, S_{\mathrm{Ic}}$, is equal to $P_{\mathrm{liq}} / P_{\mathrm{Ic}}$, where $P_{\mathrm{Ic}}$ is the vapour pressure over a flat ice $I_{c}$ surface. The difference in free energy between the two phases $\left(\Delta G_{h \rightarrow c}\right)$ was determined at $180-190 \mathrm{~K}$ from relative vapour pressure measurements to be $155 \pm 30 \mathrm{~J} \mathrm{~mol}^{-1}$ (Shilling et al., 2006). If we assume $\Delta G_{h \rightarrow c}$ is temperature independent, we can approximate the temperature dependence of $P_{\text {Ic }}$ as $P_{\mathrm{Ih}} \exp \left(\Delta G_{h \rightarrow c} / \mathrm{RT}\right)$ (Murphy, 2003; Murphy and Koop, 2005; Murray et al., 2010). The plot in Fig. 7 yields $m_{\text {Ic }}$ for kaolinite of $0.45 \pm 0.01$, which corresponds to contact angles of $63.1 \pm 0.7^{\circ}$ and $\varphi$ of $0.184 \pm 0.006$.

\section{Parameterisations to describe ice nucleation in the immersion mode}

Real atmospheric aerosols are a complex mixture of many species which may nucleate ice. The proportions of each component will not only vary in space and time in the present atmosphere, but have also changed in the past and will likely change in the future. Ideally, we would like to be able to predict the number of ice particle produced through the immersion mode under a given set of atmospheric conditions taking into account time (cooling rates) and also the surface area of solid inclusions. Here we set out a multi-component stochastic model which may provide a means with which to achieve 
this goal and show how the data obtained in the present study represents a first step in this direction.

If a droplet contains a single ice nucleus species $i$ it could freeze either homogeneously or heterogeneously. The total rate of freezing of liquid droplets in a population of similar droplets all containing particle $i$ will be the sum of the rate of homogeneous and heterogeneous nucleation:

$\frac{d N_{i}}{d t}=-R_{\mathrm{hom}}-R_{i}=-J_{\mathrm{hom}} V N_{i}-J_{i} \sigma_{i} N_{i}$

where the number of liquid droplets containing species $i$ with surface area $\sigma$ and of volume $V$ is $N_{i}$.

Integrating this equation between $t_{1}$ and $t_{2}$ yields

$\ln \frac{N_{i, 2}}{N_{i, 1}}=\left(-J_{\text {hom }} V-J_{i} \sigma_{i}\right) \Delta t$

and since $\Delta n=N_{i, 1}-N_{i, 2}$ we can state

$\Delta n=N_{i, 1}\left(1-\exp \left(-\left(J_{\text {hom }} V+J_{i} \sigma_{i}\right) \Delta t\right)\right)$

where the subscript 1 and 2 indicate the number of remaining liquid droplets at the beginning and end of the time increment ( $N_{i}$ varies with time as droplets freeze). If there is more than one ice nucleus type per $\operatorname{droplet}(i=1,2,3 \ldots)$ then the formation of ice particles can be described using a more general equation

$\Delta n=N_{1}\left(1-\exp -\left(J_{\text {hom }} V+\sum_{i} J_{i} \sigma_{i}\right) \Delta t\right)$

In the atmosphere, a cloud may consist of multiple droplet populations $(y)$ each with different ice nuclei species $(i=$ 1 or 2 or 3 , etc.) or combinations of species internally mixed ( $i=1,2,3$ or 2,4 or 3,4 etc.). The total number of populations required to approximate freezing in a particular cloud is unclear, but ice formation in each population would be described by:

$$
\Delta n_{y}=N_{y, 1}\left(1-\exp -\left(J_{\mathrm{hom}} V+\sum_{i} J_{i} \sigma_{i}\right) \Delta t\right)
$$

In addition, there may be a population which contain no ice nuclei $(y=0)$, which can only freeze homogeneously:

$\Delta n_{\mathrm{y}=0}=N_{\mathrm{y}=0,1}\left(1-\exp \left(-J_{\mathrm{hom}} V \Delta t\right)\right)$

The total ice particle production in a time step would be the sum of ice production in all populations containing ice nuclei $(y>0)$ and the population not containing any ice nuclei $(y=0)$

$\Delta n=\sum_{y} \Delta n_{y}$

This multiple component stochastic model therefore allows the determination of the number of ice particles which will be produced for any combination of heterogeneous ice nuclei (internally or externally mixed).

In order for this multiple component stochastic model to be applied, the temperature dependent nucleation rates for each type of atmospherically relevant ice nuclei will need to be determined. In combination with information about the composition of atmospheric aerosol this model will allow the prediction of ice particle production rates for a given set of meteorological conditions. The global distribution of some IN has been estimated and has been used in global modelling studies of ice formation in clouds (Hoose et al., 2008, 2010; Claquin et al., 1999).

The temperature dependent nucleation rates for homogeneous nucleation and heterogeneous nucleation on kaolinite particles, based on our data, are given by the following formula:

$J_{\text {hom }}(T)\left[\mathrm{cm}^{-3} \mathrm{~s}^{-1}\right]=\exp (-2.92 T+706.5) \quad(234.9-236.7 \mathrm{~K})$

$J_{\mathrm{k}}(T)\left[\mathrm{cm}^{-2} \mathrm{~s}^{-1}\right]=\exp (-0.8802 T+222.17) \quad(236.1-245.5 \mathrm{~K})$

The homogeneous nucleation rate coefficient is taken from Murray et al. (2010) whereas the rate coefficient for kaolinite is from the fit to the data in Fig. 5. The temperature ranges over which measurements have been made is given in brackets; extrapolation of these rate coefficients to other temperatures should be done with caution. In the future it may be sensible to use classical nucleation theory to parameterise this data (Chen et al., 2008; Hoose et al., 2010), but it would be desirable to validate such a parameterisation with experiments over a wider range of conditions.

To show that these Eqs. (16-24) are self consistent with our experimental data we have plotted the parameterised and experimental $f_{\text {ice }}(T)$ for kaolinite in Fig. 8. The total number of frozen droplets $(n(T))$ is the total number of droplets which froze on cooling to $T$ at a defined cooling rate. We calculate $n(T)$ by determining $d n$ for appropriately small increments in temperature and summing the number of droplets which froze at each increment on cooling. The resulting values of $f_{\text {ice }}(T)$ are in good agreement with our data (see Fig. 8).

Inspection of $f_{\text {ice }}(T)$ for $0.005 \mathrm{wt} \%$ kaolinite in Fig. 8 reveals that homogeneous nucleation competes with heterogeneous nucleation on the kaolinite particles. The dotted line is $f_{\text {ice }}(T)$ for heterogeneous nucleation on kaolinite only and this under predicts the experimentally determined $f_{\text {ice }}$ below $236 \mathrm{~K}$. We have also included $f_{\text {ice }}$ for homogeneous freezing only (dashed line). The rate at which droplets freeze homogeneously exceeds that at which they freeze heterogeneously at $235.7 \mathrm{~K}$ (for these specific conditions) and inclusion of both homogenous and heterogeneous nucleation yield a good fit to the data (solid line). Freezing of droplets with a $0.1 \mathrm{wt} \%$ of kaolinite is dominated by heterogeneous nucleation at this cooling rate. 
The competition between homogeneous nucleation and heterogeneous nucleation within droplets contaminated with mineral dust particles can be understood with the help of Fig. 9. In this figure we have plotted the average time required for $50 \%$ of a monodispersed population of droplets to freeze $\left(t_{50}\right)$ as a function of temperature. We have plotted two curves, the first for $20 \mu \mathrm{m}$ diameter pure water droplets which froze homogeneously and the second for droplets of unspecified volume each contaminated with a spherical kaolinite particle of $1 \mu \mathrm{m}$ diameter.

The time required for homogeneous nucleation varies much more steeply with temperature than heterogeneous nucleation on kaolinite, and these lines intersect at $236.6 \mathrm{~K}$. Below this temperature the rate of homogeneous nucleation in a $20 \mu \mathrm{m}$ droplet becomes more rapid than the rate of heterogeneous nucleation on the $1 \mu \mathrm{m}$ mineral dust inclusion. This threshold will obviously depend on the volume of the droplet and size of the kaolinite particle. Homogeneous nucleation becomes more important in larger droplets, but heterogeneous nucleation becomes increasingly important in droplets with higher surface areas of kaolinite inclusion.

In Fig. 10 we illustrate the dependence of $f_{\text {ice }}$ on cooling rate based on the parameterisations outlined in equations 1624. These calculations are for spherical kaolinite particles of $1 \mu \mathrm{m}$ diameter immersed in droplets of $20 \mu \mathrm{m}$ diameter. The size of the water droplet is only significant for the lowest temperatures (fastest cooling rates for kaolinite) where homogeneous nucleation competes with heterogeneous nucleation. On changing the cooling rate from 10 to $0.01 \mathrm{~K} \mathrm{~min}^{-1}$ the freezing curves shift to higher temperatures by $8 \mathrm{~K}$. This is in contrast to a change in just $2 \mathrm{~K}$ for homogeneous nucleation over a similar range of cooling rates. It should be noted that we have extrapolated to cooling rates well beyond those in our experimental study in Fig. 10 and nucleation should be tested at the very slow cooling rates. However, the isothermal experiments support this extrapolation since they represent experiments at an infinitely slow cooling rate.

\section{Summary and conclusions}

We present the first experimental study in which the ice nucleating ability of kaolinite in the immersion mode has been quantitatively investigated as a function of clay surface area, cooling rate and at constant sub-zero temperatures. We show that the freezing temperature during cooling scales with surface area and also show that nucleation continues when the temperature is held constant.

The stochastic, singular and modified singular models of ice nucleation can all represent the freezing data from experiments in which the droplets were cooled at a rate between 0.8 and $10 \mathrm{~K} \mathrm{~min}^{-1}$ within experimental uncertainty. However, only the stochastic model can describe droplet freezing at constant temperature and reconcile this with freezing during cooling. Overall, we conclude that the single component

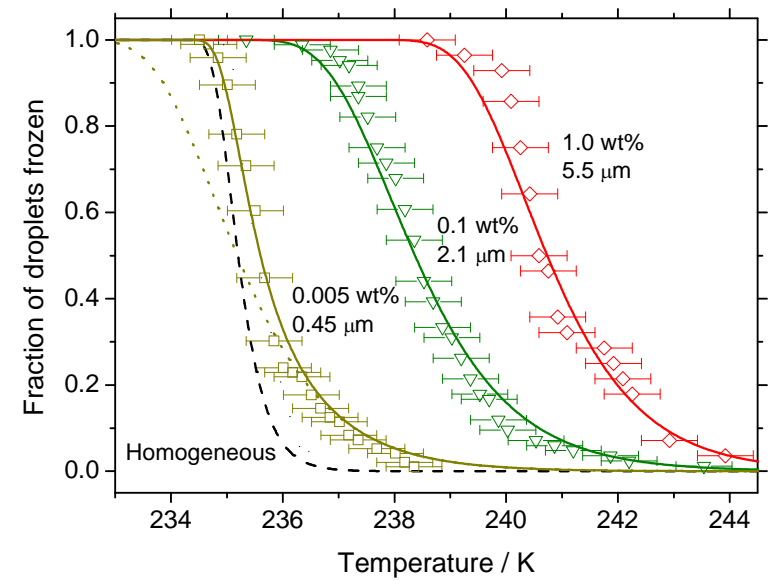

Fig. 8. Fraction of droplets frozen as a function of temperature for a range of kaolinite concentrations. Experimental data is compared with our parameterisation (solid lines) and homogeneous nucleation only (dashed line). The dotted line for the $0.005 \mathrm{wt} \%$ data is the fraction frozen if homogeneous nucleation is neglected, whereas the solid line is where both homogeneous and heterogeneous nucleation are included (Eq. 18). The radius of a single spherical clay particle that has the same surface area as the particles within a median droplet in our experiments is also given.

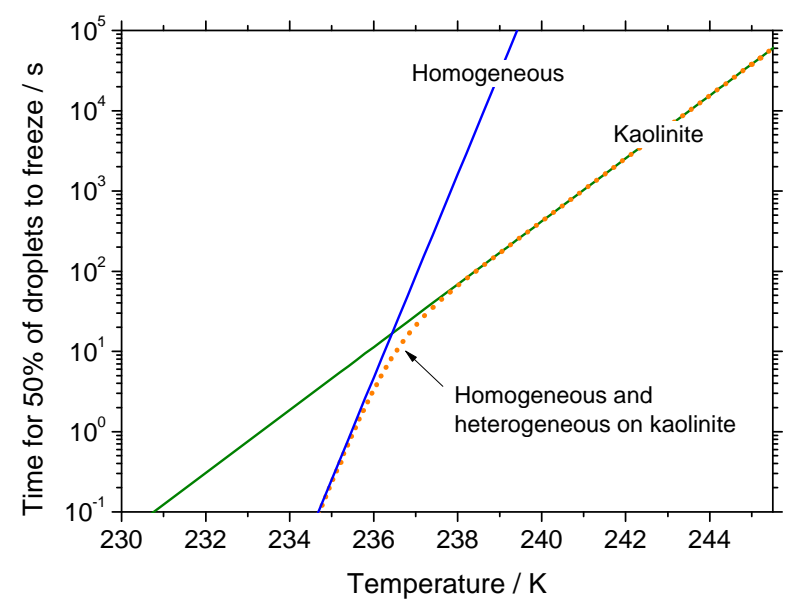

Fig. 9. The time required to freeze $50 \%$ of a population of droplets as a function of isothermal temperature. The kaolinite line (solid green) is for $1 \mu \mathrm{m}$ diameter particles suspended in droplets (no homogeneous nucleation) and the homogeneous line is for homogeneous nucleation in $20 \mu \mathrm{m}$ diameter water droplets. The combined rate of homogeneous and heterogeneous nucleation is used to derive the dotted line.

stochastic model provides the best description of nucleation by kaolinite in the immersion mode since a single temperature dependent nucleation rate coefficient can be used for both freezing during cooling and at constant temperature. 


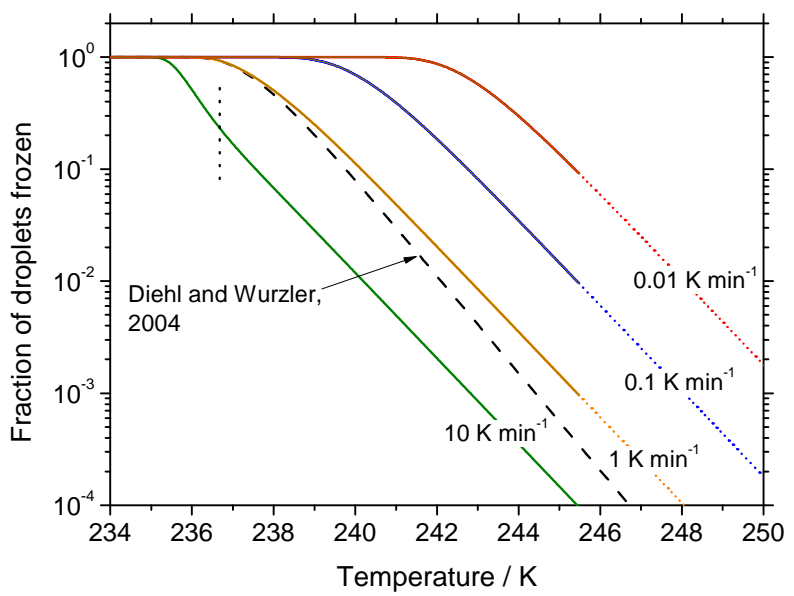

Fig. 10. Fraction of droplets frozen for a range of atmospherically relevant cooling rates for $1 \mu \mathrm{m}$ diameter kaolinite particles immersed in water droplets of $20 \mu \mathrm{m}$ diameter. These lines were calculated based on equations 16 to 24 . The vertical dotted line is the temperature below which homogeneous nucleation becomes increasingly dominant at $10 \mathrm{~K} \mathrm{~min}^{-1}$. We have compared our cooling rate dependent parameterisation with that of Diehl and Wurzler (2004) for the same droplet size. Diehl and Wurzler's parameterisation neglects the cooling rate and the surface area dependence of heterogeneous ice nucleation. The dotted portion of the lines indicates the temperature regime over which our parameterisation is extrapolated.

The use of a time dependent model for heterogeneous freezing may be most important in clouds where the cooling is slow. For example, Crosier et al. (2011) describe a midlevel stratus cloud over southern England which persisted for many hours and ice particles were observed to precipitate out of the cloud over this period. They speculate that the continued production of ice crystals must either be due to entrainment of fresh ice nuclei into the top of the cloud or slow stochastic nucleation on a large population of inefficient ice nuclei. As Vonnegut and Baldwin (1984) suggested, if the time dependent nature of ice nucleation is important in atmospheric ice nuclei then we will need to measure the rate of ice particle production in addition to the number of active ice nuclei there are at a particular temperature. This is required to distinguish between a situation in which there are a small number of particles with a high probability of nucleating ice compared to a situation with a population of a large number of particles each with only a small probability of nucleating ice. More research is required to quantify the time dependence of nucleation of ice on a range of atmospherically relevant materials in order to address these issues.

By applying classical nucleation theory, immersion mode ice nucleation by kaolinite (KGa-1b) can be described by a single contact angle which is insensitive to temperature (at least in the range of temperatures probed here). This suggests that one kaolinite particle has very similar or identical ice nu- cleating properties to another kaolinite particle and kaolinite particles of the same size have the same probability of nucleating ice under a given set of conditions. This now needs to be tested on a single particle basis and in addition we need to test if kaolinite from other sources has the same ice nucleating properties as the sample used here. Comparison with the single particle ice nucleation measurements of Lüönd et al. (2010) suggests kaolinite from different sources may vary in ice nucleating properties.

In this paper we propose that a multiple component stochastic model may lead to the ability to predict the ice nucleating properties of any natural dust or aerosol. In order to achieve this goal we will need to measure the ice nucleation rate coefficients for all of the major atmospherically relevant ice nucleating aerosol species (including mineral dusts). Measuring ice nucleation by representative natural dusts from around the world is important, but given the variability of natural dusts from different sources and the evolution of dust composition after transport it is unclear if natural dusts from surface sources are representative of atmospheric dust. Combining global distributions of atmospheric aerosol composition with nucleation data for each major aerosol species may provide a more robust method of predicting ice nucleation in the current and future climate.

Acknowledgements. We thank Zhiqiang Cui, Chris Westbrook and Ross Herbert for helpful discussions and Trevor Ingham for help with the automation of data logging. We acknowledge the Natural Environment Research Council (NE/D009308/1 and NE/H001050/1) and the European Research Council (240449-ICE) for financial support. TWW thanks the Charles Brotherton trust for a Studentship and the Aerosol Society for other financial support.

Edited by: T. Koop

\section{References}

Bereznitski, Y., Jaroniec, M., and Maurice, P.: Adsorption characterization of two clay minerals society standard kaolinites, J. Colloid. Interf. Sci., 205, 528-530, 1998.

Bickmore, B. R., Nagy, K. L., Sandlin, P. E., and Crater, T. S.: Quantifying surface areas of clays by atomic force microscopy, Amer. Mineralogist, 87, 780-783, 2002.

Bigg, E. K.: The supercooling of water, Proc. Phys. Soc., 66, 688694, 1953.

Chen, J.-P., Hazra, A., and Levin, Z.: Parameterizing ice nucleation rates using contact angle and activation energy derived from laboratory data, Atmos. Chem. Phys., 8, 7431-7449, doi:10.5194/acp-8-7431-2008, 2008.

Claquin, T., Schulz, M., and Balkanski, Y. J.: Modeling the mineralogy of atmospheric dust sources, J. Geophys. Res., 104, 22243 22256, 1999.

Connolly, P. J., Mohler, O., Field, P. R., Saathoff, H., Burgess, R., Choularton, T., and Gallagher, M.: Studies of heterogeneous 
freezing by three different desert dust samples, Atmos. Chem. Phys., 9, 2805-2824, doi:10.5194/acp-9-2805-2009, 2009.

Costanzo, P. M.: Baseline studies of the clay minerals society source clays: Introduction, Clay Clay Miner., 49, 372-373, 2001.

Crosier, J., Bower, K. N., Choularton, T. W., Westbrook, C. D., Connolly, P. J., Cui, Z. Q., Crawford, I. P., Capes, G. L., Coe, H., Dorsey, J. R., Williams, P. I., Illingworth, A. J., Gallagher, M. W., and Blyth, A. M.: Observations of ice multiplication in a weakly convective cell embedded in supercooled mid-level stratus, Atmos. Chem. Phys., 11, 257-273, doi:10.5194/acp-11-257-2011, 2011.

de Boer, G., Morrison, H., Shupe, M. D., and Hildner, R.: Evidence of liquid dependent ice nucleation in high-latitude stratiform clouds from surface remote sensors, Geophys. Res. Lett., 38, L01803, doi:01810.01029/02010GL046016, 2010.

DeMott, P. J.: An exploratory-study of ice nucleation by soot aerosols, J. Appl. Meteorol., 29, 1072-1079, 1990.

DeMott, P. J.: Laboratory studies of cirrus cloud processes, in: Cirrus, edited by: Lynch, D. K., Sassen, K., Starr, D. C., and Stephens, G., Oxford University Press, Oxford, UK, 102-135, 2002.

DeMott, P. J., Cziczo, D. J., Prenni, A. J., Murphy, D. M., Kreidenweis, S. M., Thomson, D. S., Borys, R., and Rogers, D. C.: Measurements of the concentration and composition of nuclei for cirrus formation, Proc. Natl. Acad. Sci. USA, 100, 14655-14660, 2003a.

DeMott, P. J., Sassen, K., Poellot, M. R., Baumgardner, D., Rogers, D. C., Brooks, S. D., Prenni, A. J., and Kreidenweis, S. M.: African dust aerosols as atmospheric ice nuclei, Geophys. Res. Lett., 30, 1732, doi:10.1029/2003GL017410, 2003 b.

DeMott, P. J., Prenni, A. J., Liu, X., Kreidenweis, S. M., Petters, M. D., Twohy, C. H., Richardson, M. S., Eidhammer, T., and Rogers, D. C.: Predicting global atmospheric ice nuclei distributions and their impacts on climate, P. Natl. Acad. Sci. USA, 107, 1121711222, doi:10.1073/pnas.0910818107, 2010.

Denman, K. L., Brasseur, G., Chidthaisong, A., Ciais, P., Cox, P. M., Dickinson, R. E., Hauglustaine, D., Heinze, C., Holland, E., Jacob, D., Lohmann, U., Ramachandran, S., da Silva Dias, P. L., Wofsy, S. C., and Zhang, X.: Couplings between changes in the climate system and biogeochemistry, in: Climate change 2007: The physical science basis. Contribution of working group $i$ to the fourth assessment report of the intergovernmental panel on climate change, edited by: Solomon, S., D., Qin, M., Manning, Z., Chen, M., Marquis, K. B., Averyt, M. T., and Miller, H. L., Cambridge University Press, Cambridge, UK, 2007.

Diehl, K. and Wurzler, S.: Heterogeneous drop freezing in the immersion mode: Model calculations considering soluble and insoluble particles in the drops, J. Atmos. Sci., 61, 2063-2072, 2004.

Diehl, K., Simmel, M., and Wurzler, S.: Numerical sensitivity studies on the impact of aerosol properties and drop freezing modes on the glaciation, microphysics, and dynamics of clouds, J. Geophys. Res., 111, D07202, doi:10.1029/2005JD005884, 2006.

Dogan, A. U., Dogan, M., Onal, M., Sarikaya, Y., Aburub, A., and Wurster, D. E.: Baseline studies of the clay minerals society source clays: Specific surface area by the brunauer emmett teller (bet) method, Clay Miner., 54, 62-66, 2006.

Dowell, L. G. and Rinfret, A. P.: Low-temperature forms of ice as studied by x-ray diffraction, Nature, 188, 1144-1148, 1960.
Dymarska, M., Murray, B. J., Sun, L. M., Eastwood, M. L., Knopf, D. A., and Bertram, A. K.: Deposition ice nucleation on soot at temperatures relevant for the lower troposphere, J. Geophys. Res., 111, D04204, doi:10.1029/2005JD006627, 2006.

Eastwood, M. L., Cremel, S., Wheeler, M., Murray, B. J., Girard, E., and Bertram, A. K.: The effects of sulfuric acid and ammonium sulfate coatings on the ice nucleation properties of kaolinite particles, Geophys. Res. Lett., 36, L02811, doi:02810.01029/02008GL035997, 2009.

Foster, A. L., Brown Jr., G. E., and Parks, G. A.: X-ray absorption fine-structure spectroscopy of photocatalyzed, heterogeneous as (iii) oxidation on kaolin and anatase, Environ. Sci. Technol., 32, 1444-1452, 1998.

Gerber, H. E.: Relationship of size and activity for agi smoke particles, J. Atmos. Sci., 33, 667-677, 1976.

Glaccum, R. A. and Prospero, J. M.: Saharan aerosol over the tropical north atlantic - mineralogy, Mar. Geol., 37, 295-321, 1980.

Gregg, S. L. and Sing, K. S. W.: Adsorption surface area and porosity, Academic Press, London, UK, 1982.

Hama, K. and Itoo, K.: Freezing of supercooled water droplets (ii), Pap. Met. Geophys., 7, 99-106, 1953.

Heneghan, A. F., Wilson, P. W., Wang, G., and Haymet, A. D. J.: Liquid-to-crystal nucleation: Automated lag-time apparatus to study supercooled liquids, J. Chem. Phys., 115, 7599-7608, 2001.

Heneghan, A. F., Wilson, P. W., and Haymet, A. D. J.: Heterogeneous nucleation of supercooled water, and the effect of an added catalyst, Proc. Nat. Acad. Sci., 99, 9631-9634, 2002.

Hobbs, P.: Ice physics, Oxford University Press, London, UK, 1974.

Hoffer, T. E.: A laboratory investigation of droplet freezing, J. Meteorol., 18, 766-778, 1961.

Hoose, C., Lohmann, U., Erdin, R., and Tegen, I.: The global influence of dust mineralogical composition on heterogeneous ice nucleation in mixed-phase clouds, Env. Res. Lett., 3, doi:10.1088/1748-9326/3/2/025003, 2008.

Hoose, C., Kristjánsson, J. E., Chen, J. P., and Hazra, A.: A classical-theory-based parameterization of heterogeneous ice nucleation by mineral dust, soot and biological particles in a global climate model, J. Atmos. Sci., 67, 2483-2503, doi:10.1175/2010JAS3425.1171, 2010.

Huang, J. F. and Bartell, L. S.: Kinetics of homogeneous nucleation in the freezing of large water clusters, J. Phys. Chem., 99, 3924 3931, 1995.

Jaynes, W. F., Zartman, R. E., Green, C. J., San Francisco, M. J., and Zak, J. C.: Castor toxin adsorption to clay minerals, Clay Clay Miner., 53, 268-277, 2005.

Kandler, K., Benker, N., Bundke, U., Cuevas, E., Ebert, M., Knippertz, P., Rodriguez, S., Schutz, L., and Weinbruch, S.: Chemical composition and complex refractive index of saharan mineral dust at izana, tenerife (spain) derived by electron microscopy, Atmos. Environ., 41, 8058-8074, 2007.

Khvorostyanov, V. I. and Curry, J. A.: The theory of ice nucleation by heterogeneous freezing of deliquescent mixed ccn, Part i: Critical radius, energy, and nucleation rate, J. Atmos Sci., 61, 2676-2691, 2004.

Khvorostyanov, V. I. and Curry, J. A.: The theory of ice nucleation by heterogeneous freezing of deliquescent mixed ccn. Part ii: Parcel model simulation, J. Atmos Sci., 62, 261-285, 2005. 
Knopf, D. A. and Lopez, M. D.: Homogeneous ice freezing temperatures and ice nucleation rates of aqueous ammonium sulfate and aqueous levoglucasan particles for relevant atmospheric conditions, Phys. Chem. Chem. Phys., 11, 8056-8068, 2009.

Koop, T., Luo, B. P., Biermann, U. M., Crutzen, P. J., and Peter, T.: Freezing of $\mathrm{HNO}_{3} / \mathrm{H}_{2} \mathrm{SO}_{4} / \mathrm{H}_{2} \mathrm{O}$ solutions at stratospheric temperatures: Nucleation statistics and experiments, J. Phys. Chem. A, 101, 1117-1133, 1997.

Koop, T., Ng, H. P., Molina, L. T., and Molina, M. J.: A new optical technique to study aerosol phase transitions: The nucleation of ice from $\mathrm{H}_{2} \mathrm{SO}_{4}$ aerosols, J. Phys. Chem. A, 102, 8924-8931, 1998.

Koren, I., Kaufman, Y. J., Washington, R., Todd, M. C., Rudich, Y., Martins, J. V., and Rosenfeld, D.: The bodele depression: A single spot in the sahara that provides most of the mineral dust to the amazon forest, Environ. Res. Lett., 1, 014005, doi:014010.011088/011748019326/014001/014001/014005, 2006.

Krämer, B., Hubner, O., Vortisch, H., Woste, L., Leisner, T., Schwell, M., Ruhl, E., and Baumgartel, H.: Homogeneous nucleation rates of supercooled water measured in single levitated microdroplets, J. Chem. Phys., 111, 6521-6527, 1999.

Kumar, R., Saunders, R. W., Mahajan, A. S., Plane, J. M.C., and Murray, B. J.: Physical properties of iodate solutions and the deliquescence of crystalline $\mathrm{I}_{2} \mathrm{O}_{5}$ and $\mathrm{HIO}_{3}$, Atmos. Chem. Phys., 10, 12251-12260, doi:10.5194/acp-10-12251-2010, 2010.

Lohmann, U. and Feichter, J.: Global indirect aerosol effects: a review, Atmos. Chem. Phys., 5, 715-737, doi:10.5194/acp-5-7152005, 2005.

Lohmann, U. and Diehl, K.: Sensitivity studies of the importance of dust ice nuclei for the indirect aerosol effect on stratiform mixedphase clouds, J. Atmos. Sci., 63, 968-981, 2006.

Lüönd, F., Stetzer, O., Welti, A., and Lohmann, U.: Experimental study on the ice nucleation ability of size selected kaolinite particles in the immersion mode, J. Geophys. Res., 115, D14201, doi:14210.11029/12009JD012959, 2010.

Mahowald, N. M. and Kiehl, L. M.: Mineral aerosol and cloud interactions, Geophys. Res. Lett., 30, 1475, doi:10.1029/2002GL016762, 2003.

Marcolli, C., Gedamke, S., Peter, T., and Zobrist, B.: Efficiency of immersion mode ice nucleation on surrogates of mineral dust, Atmos. Chem. Phys., 7, 5081-5091, doi:10.5194/acp-7-50812007, 2007.

Martin, S.: Phase transitions of aqueous atmospheric particles, Chem. Rev., 100, 3403-3453, 2000.

Mayer, E. and Hallbrucker, A.: Cubic ice from liquid water, Nature, 325, 601-602, 1987.

Mertes, S., Verheggen, B., Walter, S., Connolly, P., Ebert, M., Schneider, J., Bower, K. N., Cozic, J., Weinbruch, S., Baltensperger, U., and Weingartner, E.: Counterflow virtual impact or based collection of small ice particles in mixed-phase clouds for the physico-chemical characterization of tropospheric ice nuclei: Sampler description and first case study, Aeros. Sci. Tech., 41, 848-864, 2007.

Mullin, J. W.: Crystallization, 4th edn., Elsevier ButterworthHeinemann, Oxford, UK, 2001.

Murphy, D. M.: Dehydration in cold clouds is enhanced by a transition from cubic to hexagonal ice, Geophys. Res. Lett., 30, 2230, doi:2210.1029/2003GL018566, 2003.
Murphy, D. M. and Koop, T.: Review of the vapour pressures of ice and supercooled water for atmospheric applications, Q. J. Roy. Meteor. Soc., 131, 1539-1565, 2005.

Murray, B. J.: Enhanced formation of cubic ice in aqueous organic acid droplets, Environ. Res. Lett., 3, 025008, doi:025010.021088/021748-029326/025003/025002/025008, 2008.

Murray, B. J. and Bertram, A. K.: Formation and stability of cubic ice in water droplets, Phys. Chem. Chem. Phys., 8, 186-192, 2006.

Murray, B. J. and Bertram, A. K.: Laboratory studies of the formation of cubic ice in aqueous droplets, in: Physics and chemistry of ice, edited by: Kuhs, W. F., The Royal Society of Chemistry, Cambridge, UK, 417-426, 2007a.

Murray, B. J. and Bertram, A. K.: Strong dependence of cubic ice formation on droplet ammonium to sulfate ratio, Geophys. Res. Lett., 34, L16810, doi:10.1029/2007GL030471, 2007 b.

Murray, B. J. and Bertram, A. K.: Inhibition of solute crystallisation in aqueous $\mathrm{H}^{+}-\mathrm{NH}_{4}^{+}-\mathrm{SO}_{4}^{2-}-\mathrm{H}_{2} \mathrm{O}$ droplets, Phys. Chem. Chem. Phys., 10, 3287-3301, doi:10.1039/b802216j, 2008.

Murray, B. J. and Jensen, E. J.: Homogeneous nucleation of amorphous solid water particles in the upper mesosphere, J. Atmos. Sol.-Terr. Phy., 72, 51-61, doi:10.1016/j.jastp.2009.10.007, 2010.

Murray, B. J. and Plane, J. M. C.: Atomic oxygen depletion in the vicinity of noctilucent clouds, Adv. Space. Res., 31, 2075-2084, 2003.

Murray, B. J. and Plane, J. M. C.: Uptake of fe, na and k atoms on low-temperature ice: Implications for metal atom scavenging in the vicinity of polar mesospheric clouds, Phys. Chem. Chem. Phys., 7, 3970-3979, 2005.

Murray, B. J., Knopf, D. A., and Bertram, A. K.: The formation of cubic ice under conditions relevant to earth's atmosphere, Nature, 434, 202-205, 2005.

Murray, B. J., Broadley, S., Wilson, T. W., Bull, S., and Wills, R.: Kinetics of the homogeneous freezing of water, Phys. Chem. Chem. Phys., 12, 10380-10387, doi:10.1039/c003297b, 2010.

Murray, B. J., Broadley, S. L., and Morris, G. J.: Supercooling of water droplets in jet aviation fuel Fuel, 90, 433-435, doi:10.1016/j.fuel.2010.08.018, 2011.

Niedermeier, D., Hartmann, S., Shaw, R. A., Covert, D., Mentel, T. F., Schneider, J., Poulain, L., Reitz, P., Spindler, C., Clauss, T., Kiselev, A., Hallbauer, E., Wex, H., Mildenberger, K., and Stratmann, F.: Heterogeneous freezing of droplets with immersed mineral dust particles - measurements and parameterization, Atmos. Chem. Phys., 10, 3601-3614, doi:10.5194/acp-10-36012010, 2010.

Pant, A., Parsons, M. T., and Bertram, A. K.: Crystallization of aqueous ammonium sulfate particles internally mixed with soot and kaolinite: Crystallization relative humidities and nucleation rates, J. Phys. Chem. A, 110, 8701-8709, 2006.

Parsons, M. T., Riffell, J. L., and Bertram, A. K.: Crystallization of aqueous inorganic-malonic acid particles: Nucleation rates, dependence on size, and dependence on the ammonium-to-sulfate, J. Phys. Chem. A, 110, 8108-8115, 2006.

Phillips, V. T. J., DeMott, P. J., and Andronache, C.: An empirical parameterization of heterogeneous ice nucleation for multiple chemical species of aerosol., J. Atmos. Sci., 65, 2757-2783, 2008. 
Pitter, R. L. and Pruppacher, H. R.: A wind tunnel investigation of freezing of small water drops falling at terminal velocity in air, Q. J. Roy. Met. Soc., 540-550, 1973.

Pratt, K. A., DeMott, P. J., French, J. R., Wang, Z., Westphal, D. L., Heymsfield, A. J., Twohy, C. H., Prenni, A. J., and Prather, K. A.: In situ detection of biological particles in cloud ice-crystals, Nat. Geosci., 2, 398-401, doi:10.1038/NGEO521, 2009.

Prenni, A. J., Petters, M. D., Kreidenweis, S. M., Heald, C. L., Martin, S. T., Artaxo, P., Garland, R. M., Wollny, A. G., and Pöschl, U.: Relative roles of biogenic emissions and saharan dust as ice nuclei in the amazon basin, Nat. Geosci., 2, 402-405, doi:410.1038/NGEO1517, 2009.

Pruppacher, H. R. and Klett, J. D.: Microphysics of clouds and precipitation, Kluwer, Dordrecht, The Netherlands, 1997.

Richardson, M. S., DeMott, P. J., Kreidenweis, S. M., Cziczo, D. J., Dunlea, E. J., Jimenez, J. L., Thomson, D. S., Ashbaugh, L. L., Borys, R. D., Westphal, D. L., Casuccio, G. S., and Lersch, T. L.: Measurements of heterogeneous ice nuclei in the western united states in springtime and their relation to aerosol characteristics, J. Geophys. Res., 112, D02209, doi:10.1029/2006JD007500, 2007.

Sassen, K.: Dusty ice clouds over alaska, Nature, 434, 456-456, 2005.

Saunders, R. W., Möhler, O., Schnaiter, M., Benz, S., Wagner, R., Saathoff, H., Connolly, P. J., Burgess, R., Murray, B. J., Gallagher, M., Wills, R., and Plane, J. M. C.: An aerosol chamber investigation of the heterogeneous ice nucleating potential of refractory nanoparticles, Atmos. Chem. Phys., 10, 1227-1247, doi:10.5194/acp-10-1227-2010, 2010.

Shilling, J. E., Tolbert, M. A., Toon, O. B., Jensen, E. J., Murray, B. J., and Bertram, A. K.: Measurements of the vapor pressure of cubic ice and their implications for atmospheric ice clouds, Geophys. Res. Lett., 33, L17801, doi:10.1029/2006GL026671, 2006.
Stockel, P., Weidinger, I. M., Baumgartel, H., and Leisner, T.: Rates of homogeneous ice nucleation in levitated $\mathrm{H}_{2} \mathrm{O}$ and $\mathrm{D}_{2} \mathrm{O}$ droplets, J. Phys. Chem. A, 109, 2540-2546, 2005.

Stoyanova, V., Kashchiev, D., and Kupenova, T.: Freezing of water droplets seeded with atmospheric aerosols and ice nucleation activity of the aerosols, J. Aerosol Sci., 25, 867-877, 1994.

Thompson, H. A., Parks, G. A., and Brown Jr, G. E.: Dynamic interactions of dissolution, surface adsorption,, and precipitation in an ageing cobalt(ii)-clay-water system, Geochim. Cosmochim. Ac., 63, 1767-1779, 1999.

Usher, C. R., Michel, A. E., and Grassian, V. H.: Reactions on mineral dust, Chem. Rev., 103, 4883-4939, 2003.

Vali, G.: Quantitative evaluation of experimental results on the heterogeneous freezing nucleation of supercooled liquids, J. Atmos. Sci., 28, 402-409, 1971.

Vali, G.: Nucleation Terminology, Bull. Am. Met. Soc., 66, 14261427, 1985.

Vali, G.: Freezing rate due to heterogeneous nucleation, J. Atmos. Sci., 51, 1843-1856, 1994.

Vali, G. and Stansbury, E. J.: Time-dependent characteristics of the heterogeneous nucleation of ice, Can. J. Phys., 44, 477-502, 1966.

Vonnegut, B. and Baldwin, M.: Repeated nucleation of a supercooled water sample that contains silver iodide particles, J. Appl. Meteor., 23, 486-490, 1984.

Zhang, X. Y., Arimoto, R., and An, Z. S.: Dust emission from chinese desert sources linked to variations in atmospheric circulation, J. Geophys. Res., 102, 28041-28041, 1997.

Zuberi, B., Bertram, A. K., Cassa, C. A., Molina, L. T., and Molina, M. J.: Heterogeneous nucleation of ice in $\left(\mathrm{NH}_{4}\right)_{2} \mathrm{SO}_{4}-\mathrm{H}_{2} \mathrm{O}$ particles with mineral dust immersions, Geophys. Res. Lett., 29, doi:10.1029/2001GL014289, 2002. 